\title{
Health and Land-Use Courses of Action for Education for Sustainable Development in Madagascar: Teacher Perspectives on Possibilities for Implementation
}

\author{
Janna Niens ${ }^{1}$ and Susanne Bögeholz ${ }^{1,2, *}$ \\ 1 Biology Education, University of Göttingen, Waldweg 26, 37073 Göttingen, Germany; \\ janna.niens@uni-goettingen.de \\ 2 Centre of Biodiversity and Sustainable Land Use (CBL), University of Göttingen, Büsgenweg 1, \\ 37073 Göttingen, Germany \\ * Correspondence: sboegeh@gwdg.de
}

Citation: Niens, J.; Bögeholz, S. Health and Land-Use Courses of Action for Education for Sustainable Development in Madagascar: Teacher Perspectives on Possibilities for Implementation. Sustainability 2021, 13, 13308. https://doi.org/10.3390/ su132313308

Academic Editor: Graça S. Carvalho

Received: 30 October 2021

Accepted: 22 November 2021

Published: 1 December 2021

Publisher's Note: MDPI stays neutral with regard to jurisdictional claims in published maps and institutional affiliations.

Copyright: (๑) 2021 by the authors. Licensee MDPI, Basel, Switzerland. This article is an open access article distributed under the terms and conditions of the Creative Commons Attribution (CC BY) license (https:// creativecommons.org/licenses/by/ $4.0 /)$.

\begin{abstract}
Education for Sustainable Development (ESD) plays a key role in achieving the Sustainable Development Goals. However, the implementation of ESD in education remains a challenge, particularly for countries such as Madagascar. ESD needs to consider regional realities to be relevant to learners. An expert study identified health and land-use courses of action for regionally relevant ESD in northeast Malagasy primary education. However, what about teacher perspectives on the possibilities for implementing such courses of action? The present think-aloud study with 10 Malagasy primary teachers used the Integrated Behavioral Model for Water, Sanitation, and Hygiene (IBM-WASH) to analyze factors that teachers perceive to be relevant for implementing health and also-as an innovation-land-use courses of action. The IBM-WASH model is a tool for identifying opportunities and barriers to a desired health behavior. It turned out that the local school's surroundings, shared values and attitudes, and existing habits are important for implementing health and land-use courses of action. Therefore, regionally adapted health and land-use teaching should consider community-contextual, community-psychosocial, and habitual-psychosocial factors. Additionally, teachers mentioned the costs and benefits of land-use practices. Thus, land-use teaching should take the individual-technological factor into account. This paper argues for a regionally adapted ESD in teacher and school education.
\end{abstract}

Keywords: Education for Sustainable Development; Sustainable Development Goals; health; land use; primary education; Madagascar; IBM-WASH

\section{Introduction}

Education has the potential to form future change agents [1]. Sustainable Development Goal (SDG) number 4: Quality Education explicitly addresses Education for Sustainable Development (ESD) [2]. The SDGs should be reached by 2030 [2]. Yet, an integration of ESD into educational policies, curricula, and teacher training is still lacking in many countries [3]. In particular, countries with low investments in quality education, such as Madagascar, are challenged to meet the required standards for ESD [4]. In Madagascar, even basic educational facilities are often insufficient [5]. Considering the local Malagasy realities is indispensable to make ESD relevant for learners. Currently, more than $77.6 \%$ of the population lives below the poverty line of USD 1.90 a day [4,6]. Moreover, Madagascar's population faces multiple health challenges. It includes, e.g., poor sanitary and hygienic conditions, under-nutrition and malnutrition, illnesses such as plague and malaria, and further health risks [7]. The island country also has a unique biodiversity. However, it is severely threatened by factors such as unsustainable land use [8,9]. In a previous Delphi study [10], we identified health topics (related to SDGs 2, 3, and 6) and land-use topics (related to SDGs 12 and 15). The four health topics are (i) Consideration of clean water, 
sanitation, and hygiene, (ii) Consideration of food hygiene and healthy diet, (iii) Prevention of (serious) illness, and (iv) Risk avoidance. The three land-use topics are (i) Management of vanilla cultivations, (ii) Management of cultivations other than vanilla such as rice, and (iii) Soil management. Thereby, we identified courses of action corresponding to the seven topics for regionally relevant ESD teaching in primary schools in northeast Madagascar [10].

To identify starting points of ESD-related training for Malagasy primary teachers, we analyzed their procedural knowledge regarding health and land use in a questionnaire study [11]. The survey determined the teachers' estimation of the effectiveness and the possibility of the implementation of the health and land-use courses of action [11]. The study showed that health and land-use procedural knowledge is currently not promoted in initial teacher training. This highlights a need for an ESD-related reorientation of primary teacher education in Madagascar [11].

The relevance of ESD to learners can increase by developing regionally relevant teaching content in line with local realities [6]. Therefore, recommendations for ESD teaching can benefit from expert knowledge. In addition, they gain acceptance from considering the perspectives of local stakeholders, such as primary teachers [12,13]. However, there is a lack of knowledge about Malagasy teacher perspectives on the reasons for the perceived possibilities of implementation of ESD-relevant courses of action. In particular, this accounts for theory-driven analyses of possibilities for regional and local implementation.

Through the present research, we aimed to fill this gap with qualitative research. The think-aloud study identifies teacher perspectives regarding the implementation of ESD-relevant health and land-use-related courses of action. In more detail, we conducted a theory-driven qualitative analysis of teacher perspectives. For the analysis, we applied the Integrated Behavioral Model for Water, Sanitation, and Hygiene (IBM-WASH).

The IBM-WASH model is a tool that Dreibelbis et al. [14] developed to identify the opportunities for and barriers to health-conscious behavior. They distinguished several factors. We report on those factors that Malagasy primary teachers perceive as relevant for implementing courses of action that contribute to SDGs 2, 3, 6, 12, and 15. Thus, our work focuses on health- and land-use-related education. Based on the findings, the present paper argues for regionally adapted sections within primary school curricula (as part of national curricula) and corresponding teacher training. This training should qualify teachers to adapt educational content to the local and regional communities and surroundings of their schools.

\subsection{Schooling Conditions in Madagascar and the SAVA Region}

Madagascar's schooling system includes 12 years of schooling (primary school, lower secondary collège, and higher secondary lycée). However, only primary education is compulsory. Primary education comprises five years of schooling. Multiple constraints, including insufficient materials and highly underqualified teachers, impair schooling conditions at all levels. For example, the primary school success rate is only 56\% [3].

Furthermore, more than $50 \%$ of Malagasy primary teachers consider the current school curricula to be of "medium" or "bad" quality [15]. The latest revision of the school curricula was in 2015. The revision did not include regional adaptations [16], despite Madagascar being a diverse country with regional specificities. In line with that, Brias-Guinart et al. [17] argued for a regionally adapted curriculum to make education more relevant to learners.

Madagascar is divided into 16 regions. One region is the SAVA region in its northeast. It encompasses the districts of Sambava, Antalaha, Vohemar, and Andapa. The SAVA region recently profited from the high price phases of the exported vanilla. It is more prosperous than southern Malagasy regions. The SAVA region belongs to the former province Antsiranana. Antsiranana had one of the country's highest primary school success rates in 2015 with $87.3 \%$ (Antananarivo: 87.5\%; other provinces: $41.0-72.3 \%$ ).

Within the scope of the latest educational development plan, the Plan Sectoriel de l'Éducation, Madagascar aims to further develop school curricula and teacher training [18]. An additional area of focus was the reorientation of education toward ESD [18]. 


\subsection{Education for Sustainable Development in Madagascar}

To date, ESD has been only marginally integrated into Malagasy primary education $[12,19]$. However, a qualitative analysis of the latest primary school curricula from 2015 [16] revealed links to several SDGs, including SDGs 2, 3, 6, 12, and 15 [20].

Apart from school education, international organizations play an essential role in health education [21-23], and environmental education [12], two facets of ESD. However, it happens that such organizations concentrate on Eurocentric rather than regional perspectives. For example, in Malagasy villages, the promotion of latrine use instead of open defecation has been negatively affected by beliefs and taboos. Unfortunately, this was not considered in latrine construction [24]. Neglecting local perceptions also hinders a positive impact of environmental education interventions. For example, the Ako-book, a school book developed to increase awareness regarding lemurs and their conservation [25], chose the Aye-aye (Daubentonia madagascariensis) for the main character. The impact of the intervention may have been negatively influenced [12] by regional views. They regard the Aye-aye as a "scary" animal [26] that is associated with evil [27]. These two examples highlight that the integration of ESD themes into education requires an adaptation of the regional context.

\subsection{Health and Land-Use Issues in Madagascar}

Sanitation, a medical infrastructure, and the broad provision of clean water are still insufficient in Madagascar, particularly in rural areas [28]. Furthermore, bad hygienic conditions and the resulting diseases [29,30], malaria [31], and under-nutrition and malnutrition [32] are still significant health issues. In addition, increasing traffic, inadequate pesticide use, and bad waste management also cause serious health risks [7]. Improved health behavior can substantially contribute to better health $[14,29]$. To promote improved health behavior, it is crucial to consider multiple factors relevant for the implementation of health courses of action [14]. These factors may include opportunities and challenges of implementation related to local "setting and/or environment" (contextual factor), "behavioral, social or psychological determinants" (psychosocial factor), or "specific attributes of a product or technology" (technological factor) [14], p. 6.

Madagascar and the SAVA region have a strong agricultural sector. In the SAVA region, rice and vanilla are the main crops [33]. Vanilla production brings economic benefits to farmers during phases of high vanilla prices. That made the crop's production even more popular in the SAVA region [33]. Vanilla agroforestry also plays an important role in biodiversity conservation in northeast Madagascar's agricultural landscape [34,35]. Nonetheless, land scarcity, deforestation, and decreasing biodiversity are still pressing challenges [36-38]. Unsustainable land use, such as slash-and-burn agriculture for hill rice production, contributes to the degradation of biodiversity and soils [39,40]. Land-use decisions are driven by multiple factors, "including socio-economic, ecological, and cultural aspects" [41], p. 74. Thus, as for improved health behavior, contextual, psychosocial, and technological factors [14] may play important roles in promoting sustainable land use. For improving corresponding pro-environmental behavior, it is necessary to understand the multiple factors that influence regional and local land-use decisions [41]. Such knowledge on reasons that affect the implementation of health and land-use courses of action is important for designing educational interventions for ESD.

\subsection{Factors of the IBM-WASH Model Relevant for Sustainable Behavior}

Factors that are relevant for sustainable behavior related to improved health and sustainable land-use decisions are often complex and interconnected. Thus, their analyses may require an interdisciplinary approach [14,41]. Dreibelbis et al. [14] developed a theoretical framework for analyzing such factors. The framework supports the development of data collection tools and data analyses. It contributes to a better understanding of health-conscious behavior [14]. The framework is based on a systematic review of models regarding water, sanitation, and hygiene (WASH) behavior. These previous models have 
different foci. For example, they address the psychological drivers of health behavior [42], habits and emotions as relevant determinants for handwashing [29], and communication models for drinking water treatment and storage [43]. Most models only considered determinants on the individual level [14]. However, Dreibelbis et al. [14] argued that understanding health behavior requires the consideration of multiple levels. Therefore, the IBM-WASH framework (synonymously referred to in the following as the IBM-WASH model) considers different dimensions as well as different levels.

In sum, the IBM-WASH model consists of three different dimensions: contextual, psychosocial, and technological. Each dimension is further divided into five levels: structural, community, interpersonal/household, individual, and habitual. The latter results in 15 different factors [14]. These different factors "should be viewed as dynamic and interrelated" [14], p. 10.

The IBM-WASH model has already been used in qualitative and quantitative analyses of various WASH interventions studies in developing countries around the world (see Table A1 in Appendix A). The model, which was developed in a research setting in Bangladesh [44], has been predominantly applied in research in South Asia (Table A1). For example, the model contributed to evaluating specific technologies for improving WASH behavior, such as handwashing stations [44,45], double-pit latrines [46], siphons for drinking water treatment [47], and a mobile health program [48]. The IBM-WASH model was also applied to evaluate a WASH intervention for reducing improper trash disposal in communal toilets [49] and a combination of various interventions, such as hygiene education, provision of hardware, and WASH events [50]. Furthermore, the IBMWASH model has been used to understand the opportunities and challenges for a specific behavior, such as hygiene practices in food preparation [51,52]. The IBM-WASH model has also been applied in South America to evaluate WASH technologies, such as drinking water chlorination [53] and baby bottle disinfection [54], as well as to understand behavior regarding latrine use [55]. To date, the IBM-WASH model has only rarely been used in research settings in Africa. Nonetheless, it has already contributed to understanding health behavior in sub-Saharan-Africa. This includes handwashing in Burundi [56] and latrine use in Ethiopia [57,58]. To the best of our knowledge, the model has not been applied in qualitative and/or quantitative health or health educational research in Madagascar. The IBM-WASH model is a suitable tool for gaining knowledge about the reasons for perceived implementation possibilities of health courses of action in Madagascar. For an overview of previous studies that applied the IBM-WASH model, see Table A1 in Appendix A.

In qualitative and quantitative studies, the IBM-WASH model has helped to identify multidimensional and multi-level opportunities and challenges for sustained health behavior $[44,47,48,50,57,58]$. Thus, it is a prerequisite for developing and implementing appropriate health interventions and technologies [57]. This applies, likewise, to regionally adapted education that considers health courses of action. To avoid teaching content that is inappropriate due to the application of Eurocentric perspectives (Section 1.2), it is indispensable to know the regional possibilities for implementing improved health behavior and sustainable land use. To date, the IBM-WASH model has only been applied in WASH-related research. To the best of the authors' knowledge, it has so far not been applied in other fields of health (e.g., avoidance of traffic risks, malaria prevention), or even beyond health in land-use settings. As for health behavior, understanding land-use decisions and pro-environmental behavior requires an approach that considers multiple factors [41]. Therefore, the IBM-WASH model might be transferable to analyzing landuse courses of action. An application of the IBM-WASH model represents a promising approach to identifying prerequisites for regionally adapted health and land-use teaching and learning.

\subsection{Research Questions}

The present study aimed at learning more about primary teacher perspectives on the possibilities for implementing health and land-use courses of action in school education. 
Our qualitative research focuses on systematically analyzing possibilities for implementing such courses of action theory-driven via the IBM-WASH model. Therefore, this study provides deep insights into teacher perspectives regarding the implementation possibilities for regionally relevant ESD. On the one hand, this study on teacher perspectives is a stand-alone study. It aims to identify reasons for perceived implementation possibilities of ESD-related courses of action. This equates insights into teaching and learning prerequisites for ESD of primary teachers. On the other hand, it complements previous studies on healthand land-use-related ESD in primary education regarding expert knowledge and teacher knowledge [10,11]. Expert knowledge, teacher knowledge, and teacher perspectives (as analyzed in the present paper) are important for designing ESD according to the SDGs for teacher and school education.

Getting to know teacher perspectives on the possibilities for implementing health and land-use courses of action in the SAVA region can contribute to carefully adapting teaching content to regional realities (regionally relevant ESD). The multidimensional and multi-level IBM-WASH model might be a suitable tool for identifying relevant factors underlying the reasons for implementation possibilities regarding ESD-related courses of action. This leads to the following research questions (RQs):

RQ 1: Which factors do Malagasy primary teachers perceive to be relevant for implementing health-related courses of action in teaching ESD?

RQ 2: Which factors do Malagasy primary teachers perceive to be relevant for implementing land-use-related courses of action in teaching ESD?

RQ 3: In what way do Malagasy primary teachers perceive that health- and land-userelated courses of action differ in their possibilities of implementation for ESD?

\section{Method and Approach}

\subsection{Measurement Instrument}

For the present think-aloud study with Malagasy primary teachers, we used the measurement instrument introduced by Niens et al. [10]. The questionnaire includes reliable subscales regarding different health and land-use topics [10]. We developed a valid instrument for measuring procedural knowledge of Malagasy primary teachers [11]. It includes ESD-related courses of action relevant in primary education. As in the study on teacher knowledge, the participants estimated the same courses of action in the present study on teacher perspectives regarding the possibility of implementation. We used a fourpoint Likert scale (1: "impossible to implement", 2: "difficult to implement", 3: "possible to implement", 4: "easy to implement").

The health context comprised 21 courses of action in 4 topics. The topic Clean water, sanitation, and hygiene includes courses of action regarding daily hygiene and sanitation practices. Examples are handwashing, teeth brushing, and latrine use, as well as drinking water treatment. Courses of action in Food hygiene and healthy diet refer to the hygienic preparation of healthy meals and a balanced diet. In Prevention of (serious) illness, courses of action included general health care and malaria prevention. The topic Risk avoidance comprised the prevention of traffic risks, protection from polluted air and pesticides, and waste management. Regarding health, we analyzed teacher estimations of the possibility of implementation of courses of action in rural and urban life.

The land-use context covered 20 courses of action in three topics. The topic Management of vanilla cultivations included courses of action regarding sustainable vanilla agroforestry. Courses of action regarding Management of cultivations other than vanilla referred to sustainable management of rice cultivations and arable land in general. Soil management contained courses of action for sustainable soil management in vanilla cultivations, rice cultivations, and arable land in general. Regarding land use, we analyzed the teacher estimations of the possibility of implementing courses of action in rural life. 


\subsection{Think-Aloud Method}

For the qualitative analysis, we applied the think-aloud method [59]. The method is a common procedure in educational and psychological research, as well as in research on problem-solving [60-62]. During a think-aloud procedure, participants express their unfiltered thoughts while executing a specific task [63]. It is a standard procedure to record the verbal statements and transcribe the recording for later analysis [63]. The generated data give "useful insights into cognitive processes of the human mind" [63], p. 303, and allow for information on subjective worldviews, emotions, motivations, and routines [64].

\subsection{Sample Composition}

The sample consisted of 10 primary teachers $(n($ female $)=5 ; n($ male $)=5)$ that teach in public schools $(n=7)$, private schools $(n=2)$, and a community school $(n=1)$. They came from urban $(n=4)$ and rural $(n=6)$ areas in the SAVA region. The schools are located in the four different districts: Sambava $(n=4)$, Andapa $(n=3)$, Vohemar $(n=1)$, and Antalaha $(n=2)$. The teachers were between 31 and 53 years old (mean: 37.8; standard deviation (SD): 9). Their years of teaching experience ranged from 5 to 18 (mean: 9.9; SD: 3.6). The highest level of school education completed by the teachers was the lower secondary Brevet d'Étude Primaire Complémentaire (BEPC) $(n=6)$ or higher secondary Baccalauréat (BACC) $(n=4)$.

\subsection{Procedure for the Think-Aloud Study}

We conducted the think-aloud study in 2018 in standardized settings. Each setting comprised one field assistant and one study participant. In the first step, a trained Malagasy assistant explained the study procedure to the teacher. The study did not start until informed consent was received. We used the following procedure: First, the teachers read out loud the instructions for "thinking aloud". Next, they performed short warm-up exercises, such as calculating the exact number of hours they need for food preparation per week. This training in thinking aloud helps to meet the requirements of think-aloud studies [63]. While working on the task, the teachers verbally expressed their thoughts.

When the teachers filled out the paper questionnaire measuring procedural knowledge, they continued the verbal expression of their thoughts. During this think-aloud procedure, the assistant did not intervene unless the teacher had questions or stopped expressing thoughts aloud. In these cases, the assistant answered the questions or asked the teachers to continue thinking aloud. The study was conducted entirely in Malagasy. During each think-aloud recording, the first author passed by the study setting two to three times to monitor if the standardized procedure (see above) was being followed. However, the first author stayed predominantly in the background to avoid intimidation of the teachers. Furthermore, this permitted a relaxed atmosphere for the verbal expression of the teachers thoughts. The think-aloud procedure was recorded in Malagasy, transcribed in Malagasy by a local assistant, and subsequently translated into French. To ensure data quality, the Malagasy transcripts and the French translations were entirely cross-checked by a second local assistant.

\subsection{Data Analysis}

The French think-aloud protocols were qualitatively analyzed with the IBM-WASH model from Dreibelbis et al. [14] according to Mayring [65]. Considering the model's three dimensions, the contextual dimension refers to the local setting or environment (e.g., access to resources, wealth, available space). Second, the psychosocial dimension includes behavioral, social, and psychological determinants (e.g., traditions, attitudes, knowledge, habits). Third, the technological dimension focuses on the characteristics of a technology or product (e.g., access to or the convenience of a product, such as soap or toothpaste). Each dimension has five levels: The societal/structural level (in the following: structural level) considers "organizational, institutional, or cultural" determinants [14], p. 6. On the community level are factors regarding the social and physical environment. The interper- 
sonal/household level (in the following: interpersonal level) refers to interactions between individuals, including roles and norms. The individual level considers sociodemographic determinants, as well as individual attitudes. The habitual level encompasses repeated behavioral outcomes [14].

The 3 dimensions and 5 levels result in 15 factors that served as deductive categories for qualitative analysis. The descriptions of these factors were inductively adapted (Table 1). The analysis was conducted with Microsoft Excel 2013. In the first step of data analysis, two coders independently analyzed $30 \%$ of the material, compared the results, and refined the coding system if needed (Table 1). The refining procedure included the following adaptations to the contextual, psychosocial, and technological dimensions and their levels (see [66]):

Table 1. The Integrated Behavioral Model for Water, Sanitation, and Hygiene (IBM-WASH model), with 15 factors (5 levels combined with 3 dimensions); adapted from Dreibelbis et al. [14] for the qualitative analysis of think-aloud protocols regarding the possibilities for implementing health and land-use courses of action. Inductive additions are in italics. Inductively motivated deletions are erossed out. The table includes contributions by Schneider [66].

\begin{tabular}{|c|c|c|c|}
\hline Level & Contextual Dimension & Psychosocial Dimension & Technological Dimension \\
\hline $\begin{array}{l}\text { Structural/ } \\
\text { Societal }\end{array}$ & $\begin{array}{c}\text { Policy and regulations; } \\
\text { climate, geography, ecology }\end{array}$ & $\begin{array}{l}\text { Leadership, advocacy; } \\
\text { cultural identity; } \\
\text { ethnic traditions and taboos }\end{array}$ & $\begin{array}{l}\text { Manufacturing and financing of a } \\
\text { product; distribution of a product; } \\
\text { current and past national policies; } \\
\text { promotion of products a course } \\
\text { of action }\end{array}$ \\
\hline Community & $\begin{array}{l}\text { Access to markets and/or corresponding } \\
\text { product availability; access to resources; } \\
\text { built and physical environment; access } \\
\text { to products with supporting function for } \\
\text { the implementation of a course of action; } \\
\text { general available space/general available } \\
\text { arable land; general wealth; infrastructure }\end{array}$ & $\begin{array}{l}\text { Shared values and/or attitudes; } \\
\text { collective efficacy; } \\
\text { social integration; stigma; } \\
\text { prevalent emotions; missing shared } \\
\text { knowledge; shared knowledge; } \\
\text { missing shared awareness; } \\
\text { shared awareness }\end{array}$ & $\begin{array}{l}\text { Location/access/availability of the } \\
\text { product that is indispensable for the } \\
\text { implementation of a course of action } \\
\text { and without the reason of } \\
\text { access/availability being the focus; } \\
\text { individual vs. collective } \\
\text { ownership/access; maintenance of } \\
\text { the product }\end{array}$ \\
\hline $\begin{array}{l}\text { Interpersonal/ } \\
\text { Household }\end{array}$ & $\begin{array}{c}\text { Roles and responsibilities; household } \\
\text { structure; division of labor; available } \\
\text { space / available arable land on } \\
\text { household level }\end{array}$ & $\begin{array}{l}\text { Injunctive or descriptive norms; } \\
\text { aspirations; shame; nurture }\end{array}$ & $\begin{array}{l}\text { Sharing of access to product; } \\
\text { modeling/demonstrating use of } \\
\text { the product }\end{array}$ \\
\hline Individual & $\begin{array}{l}\text { Individual wealth; age; } \\
\text { education; gender; } \\
\text { livelihoods/employment }\end{array}$ & $\begin{array}{l}\text { Self-efficacy; disgust; perceived } \\
\text { threat; knowledge }\end{array}$ & $\begin{array}{l}\text { Perceived cost/value/cost-benefit } \\
\text { relation; perceived convenience; } \\
\text { ease of execution; difficulty of execution } \\
\text { other strengths and weaknesses of } \\
\text { the product course of action }\end{array}$ \\
\hline Habitual & $\begin{array}{l}\text { Favorable environment for habit } \\
\text { formation; opportunity for and barriers } \\
\text { to repetition of behavior }\end{array}$ & $\begin{array}{l}\text { Existing water and sanitation } \\
\text { habits; outcome expectation; } \\
\text { existing practices }\end{array}$ & $\begin{array}{l}\text { Ease/effectiveness of routine use of } \\
\text { product/implementation of course } \\
\text { of action }\end{array}$ \\
\hline
\end{tabular}

Contextual dimension: An adaptation to the land-use context is the addition of ecology to the structural-contextual factor. On the community level, we further narrowed the description to differentiate the community-contextual from the community-technological factor: First, we specified in the community-contextual factor the aspect "access to markets" with "and/or the corresponding product availability". Second, we added here the aspect "access to products with supporting function for the implementation of a course of action". A further adaptation was the addition of "infrastructure" as the teachers mentioned it in the health context. According to our coding system, infrastructure included not only traffic but also sanitary infrastructure, such as access to community water taps and latrines [57], as well as access to medical treatment. Furthermore, we differentiated between general available space or general wealth (community level) and available space on a household level (interpersonal) or individual wealth (individual level), respectively. We decided to apply this differentiation because most of the teachers explicitly referred to general available space (e.g., for agricultural land use) surrounding their community or the general 
wealth in the region (community level). Sometimes they mentioned specific examples, such as "if a person ..." (interpersonal/individual level). In addition, we extended the term "available space" by adding "available arable land" to make it more applicable to the land-use context.

Psychosocial dimension: To the structural level, we added ethnic traditions and taboos because they play an important role in Madagascar and were mentioned by some teachers. In contrast to the original model, associations with "knowledge" were not coded as individualpsychosocial factor but as community-psychosocial factor: Teachers always referred to a group of people with expressions such as "the people know" or "in the village, [ ... ]". Furthermore, we added "missing shared knowledge", "(missing) shared awareness", "prevalent emotions", and "shared attitudes" to the community-psychosocial factor because corresponding references appeared in our data. Regarding the habitual-psychosocial factor, the original model included the aspect "outcome expectation" [14]. During analysis, it was too difficult to distinguish this aspect from the individual-technological factor relating to the perceived value and convenience of a product. Therefore, we excluded the aspect "outcome expectation" from the model. To adapt the habitual-psychosocial factor to the land-use context, we changed "existing water and sanitation habits" into "existing habits". We also added "existing practices" to the habitual-psychosocial factor because the teachers referred to existing and usual land-use practices that are regularly executed, for instance, as tradition or habit.

Technological dimension: We made an important adaptation in the technological dimension by considering the individual courses of action as technology. Other studies that used the IBM-WASH model for qualitative analysis only focused on evaluating a specific technology (e.g., latrines, handwashing stations; cf. [44,46,48,67]). Instead, we focused on the estimation of courses of action for diverse health and land-use topics in terms of their possibility of implementation. On the community level, we specified the aspect "location/access/availability of the product" to distinguish it from the description of the community-contextual factor (see above). Therefore, we defined the aspect as " $[\ldots]$ the product that is indispensable for the implementation of a course of action and without the reason of access/availability being the focus". Furthermore, we extended the "perceived cost/value" of the individual-technological factor by adding "cost-benefitrelation". We added it because the teachers explicitly referred to the agronomic benefit in the land-use context. In addition, we added the aspects "ease of the execution" and "difficulty of execution" to the individual-technological factor; they occurred several times in our data.

Regarding the procedure in qualitative data analysis, we first defined coding units in the think-aloud protocols. One coding unit could be one word up to a whole paragraph. Second, we assigned a coding unit to 1 of the 15 factors of the IBM-WASH model. We did not allow double coding for one coding unit. Thus, each coding unit was associated exclusively with one factor. In the following, we use the term "coding" for an assignment of a coding unit to a factor.

We provide the complete final coding system for analyzing the think-aloud protocols in Table A2 in Appendix B, cf. [66]. The provided tool comprises the coding guidelines and anchor examples as required for qualitative analysis according to Mayring [65]. Based on the final coding system, all of the material was analyzed again by the two coders. Then, they compared the codings, identified deviating preliminary assignments, and discussed them to reach consensus. During the comparison of the complete analysis of the two coders, the number of matched and mismatched codings were noted. With these numbers, we calculated the reliability coefficient following the procedure in Döring and Bortz [68]. The resulting value of intercoder reliability was $62.3 \%$, which is further discussed in Section 4.5. In case of a remaining disagreement for codings between the two coders, the unclear codings were discussed until consensus was reached within a group of four researchers in the field of biology education. 
In line with Hulland et al. [44], McMichael and Robinson [50], and Alemu et al. [58], we present the results according to the five different levels of the IBM-WASH model. The results are illustrated with quotes from the think-aloud protocols of the participants, followed by a pseudonymized indication of the specific teacher. If not stated otherwise, all citations represent opinions from a minimum of three different teachers.

\section{Results}

To answer RQ 1: "Which factors do Malagasy primary teachers perceive to be relevant for implementing health-related courses of action in teaching ESD?" and RQ 2: "Which factors do Malagasy primary teachers perceive to be relevant for implementing of landuse-related courses of action in teaching ESD?", we proceeded as follows: We first give a quantitative overview of the distribution of health-related codings and then of landuse-related codings in the qualitative data with respect to the 15 factors (levels combined with dimensions, Sections 3.1 and 3.2). Second, we go into more detail and shed light on teacher perceptions from a qualitative perspective; here, we use citations for illustration (Sections 3.1 and 3.2).

The quantitative distribution of the codings is presented as a percentage of the total number of codings per topic/context. To interpret the data, it must be considered that the total number of codings in the health context (194 codings) compared to the land-use context (74) was generally higher. This difference results from the different structure of the questionnaire for the two contexts [10]: While the health courses of action were estimated twice regarding their possibility of implementation (in rural and in urban areas), the courses of action in the land-use context were only estimated once (regarding rural areas). Furthermore, the total number of codings differed across the four health and three land-use topics. To compare the factor distributions across the topics and contexts, the total number of codings behind the percentages needs to be considered.

With respect to the description of the results of the qualitative analyses, we presented them in the following order from the structural to the habitual level of the IBM-WASH model. As no coding appeared on the interpersonal level in the health context and only two codings appeared on the interpersonal level in the land-use context, the interpersonal level was not considered in the description of the qualitative data. For each level, the dimensions are presented in descending order, the dimension with the highest number of codings presented first.

Each of the 15 factors comprises several different aspects (e.g., for the structuralcontextual factor: "policy and regulations", "climate and geography", "ecology"; Table 1). If the qualitative data in the complete health or land-use context provided three or more codings by three different teachers for one aspect, we gave one exemplary citation. If less than three citations existed, the number of teachers sharing this statement was mentioned, or no example was given. As the land-use context has a lower total number of codings (see above), the hurdle for citations to be presented is higher and single opinions are represented more often than in the health context.

\subsection{Relevant Factors for Implementing Health Courses of Action}

Table 2 shows the general pattern of the coding distribution in the four health topics and the complete health context (RQ 1). The number of codings per health topic ranges from 29 (Risk avoidance) to 94 (Clean water, sanitation, and hygiene).

Across all four topics, the teachers predominantly referred to contextual, psychosocial, and technological dimensions on the community level, including access to markets, shared values, attitudes, knowledge, and access to specific products. However, Risk avoidance shows a lower share of codings regarding the community-psychosocial factor when compared to the other three topics.

A further similarity among all four health topics is the high share of codings associated with the habitual-psychosocial factor referring to existing habits. Factors on the structural level were mentioned almost exclusively under the topic Prevention of (serious) illness. Here, 
most codings addressed the distribution of mosquito nets provided by the state. The individual level only appeared under the topics Clean water, sanitation, and hygiene and Food hygiene and healthy diet, predominantly in the technological dimension, referring to, for instance, the ease or the value of the related courses of action. In sum, we identified factors that are relevant for implementing health courses of action on four out of five levels of the IBM-WASH model, i.e., on the structural, community, individual, and habitual level.

Table 2. Distribution of codings per factor, based on the IBM-WASH model, as percentage for each of the four health topics and the complete health context. Percentages greater than 10.0 are bolded. The table includes unpublished results from Schneider [66].

\begin{tabular}{|c|c|c|c|c|c|c|}
\hline Level & Dimension & $\begin{array}{c}\text { Clean Water, } \\
\text { Sanitation, and } \\
\text { Hygiene } \\
\text { (94 Codings) }\end{array}$ & $\begin{array}{c}\text { Food Hygiene } \\
\text { and } \\
\text { Healthy Diet } \\
\text { (37 Codings) }\end{array}$ & $\begin{array}{l}\text { Prevention of } \\
\text { (Serious) } \\
\text { Illness } \\
\text { (34 Codings) }\end{array}$ & $\begin{array}{c}\text { Risk } \\
\text { Avoidance } \\
\text { (29 Codings) }\end{array}$ & $\begin{array}{c}\text { Health } \\
\text { Context } \\
\text { (194 Codings) }\end{array}$ \\
\hline \multirow{3}{*}{$\begin{array}{l}\text { Structural/ } \\
\text { Societal }\end{array}$} & Contextual & - & - & 5.9 & 3.4 & 1.5 \\
\hline & Psychosocial & - & - & - & - & - \\
\hline & Technological & - & - & 20.6 & - & 3.6 \\
\hline \multirow{3}{*}{ Community } & Contextual & 34.0 & 37.8 & 29.4 & 48.3 & 36.1 \\
\hline & Psychosocial & 16.0 & 13.5 & 14.7 & 6.9 & 13.9 \\
\hline & Technological & 20.2 & 21.6 & 14.7 & 31.0 & 21.1 \\
\hline \multirow{3}{*}{$\begin{array}{l}\text { Interpersonal/ } \\
\text { Household }\end{array}$} & Contextual & - & - & - & - & - \\
\hline & Psychosocial & - & - & - & - & - \\
\hline & Technological & - & - & - & - & - \\
\hline \multirow{3}{*}{ Individual } & Contextual & 1.1 & 2.7 & - & - & 1.0 \\
\hline & Psychosocial & - & - & - & - & - \\
\hline & Technological & 8.5 & 10.8 & - & - & 6.2 \\
\hline \multirow{4}{*}{ Habitual } & Contextual & 6.4 & - & - & - & 3.1 \\
\hline & Psychosocial & 12.8 & 13.5 & 14.7 & 10.3 & 12.9 \\
\hline & Technological & 1.1 & - & - & - & 0.5 \\
\hline & & 100.0 & 100.0 & 100.0 & 100.0 & 100.0 \\
\hline
\end{tabular}

\subsubsection{Structural Level}

The study participants only occasionally mentioned factors on the structural level (in sum, 5.1\% of all codings). These codings belonged to the technological and contextual dimension. In the technological dimensions, four participants mentioned the distribution of mosquito nets by the state as protection from malaria (Topic Prevention of (serious) illness). Such a distribution strongly promotes frequent use: "Implementation in rural life, this is [... ] easy to implement because the state has already distributed mosquito nets to everybody" [AH-02, 150-151]. Likewise, the access to free health care (e.g., deworming) provided in health centers and schools (Prevention of (serious) illness) was positively mentioned [AE-01, AH-02, L-07] (structural-technological factor). Regarding the contextual dimension, only two comments appeared [L-07, M-05] on geography or climate (Prevention of (serious) illness) and one comment [AF-11] appeared regarding policy regulations (Risk avoidance).

\subsubsection{Community Level}

With $71.1 \%$ of all codings, the community level was the most frequently addressed level for the health context. Here, most of the statements appeared in the contextual dimension. Access to resources such as water for body and food hygiene, as well as access to cultivated fruits and vegetables and firewood, were relevant for implementing the investigated courses of action. This accounts particularly for the topics Clean water, sanitation, and hygiene and Food hygiene and healthy diet. For example, water resources are easy to access: "If it is in the village, this must be easy to implement, [ ... ] because if it is a place that has a river, it is easy to wash the hands" [AG-01,35-39] (Topic Clean water, sanitation, and hygiene, contextual dimension). In contrast, the preparation of balanced meals can be difficult: "Implementation in rural life, it is difficult to implement because in the bush, there are 
no vegetables, only maniocs or things like that" [Y-02, 191-192] (Food hygiene and healthy diet, contextual dimension).

Furthermore, the teachers mentioned infrastructure, such as water taps and latrines, access to the nearest health center or hospital, or the traffic density, when they evaluated the possibility of implementing of the courses of action. For example, Clean water, sanitation, and hygiene "is also easy to implement because there are already many water taps in the city" [AH-02, 165-166] (contextual dimension). Two teachers [AH-02, L-07] argued that long distances can hinder the Prevention of (serious) illness: "In the rural life, it is difficult to implement because there are certain places that are far from the hospital" [AH-02, 190-191]. For urban life, the situation is better: "In the urban life, it is easy to implement because there exist numerous different hospitals" [AH-02, 191-192] (contextual dimension for both citations). Regarding accidental risks and exposure to bad air (Topic Risk avoidance), the traffic density plays a critical role: "It is easy to implement in the village because [... ] it is rare that you find cars that come here [...] But in the city, it is difficult to implement because there are many cars that circulate" [M-05, 256-257] (contextual dimension). Furthermore, the teachers mentioned the general wealth (contextual dimension) as a relevant determinant for implementing the courses of action. For example, one teacher [AE-01] connected the general wealth to several courses of action across all four topics, including the purchase of chlorine for water disinfection (Topic Clean water, sanitation, and hygiene), fruits and vegetables (Food hygiene and healthy diet), and protective clothing for pesticide use (Risk avoidance) as well as latrine construction (Clean water, sanitation, and hygiene), and transport costs to distant health centers (Prevention of (serious) illness). For example, with regard to the safe storage of drinking water, the participant said: "[ ... ] [the people] can implement it but like I said, the means, sometimes [the means] are not there. Often maybe if you want to buy a bucket to store it, it is already difficult [... It is the means that are very difficult for the people in the village" [AE-01, 166-170] (Clean water, sanitation, and hygiene).

Whenever a course of action implied, the purchase of specific products, such as soap, water filter, toothpaste, fruits, or protective clothing, the teachers often perceived access to markets (contextual dimension) or the access to specific products (technological dimension) as relevant for the implementation. While some products (e.g., soap) or activities (e.g., water boiling) for Clean water, sanitation, and hygiene and Food hygiene and healthy diet are often easily accessible, water disinfection (Sur'Eau), water filters, and toothpaste were often described as difficult to access (technological dimension), particularly in rural areas: "[Drinking water treatment] is difficult to implement because in the bush, there is no Sur'Eau [chlorine for water disinfection]" [Y-02, 100] (Topic Clean water, sanitation, and hygiene). Likewise, the teachers mostly perceived it as difficult to find clothing for body protection during pesticide use (Risk avoidance) in the village: "Implementation in the rural life, this is difficult to implement. There, there is neither a mask, nor a working suit, nor glasses, nothing" [Y-02, 245-246].

The teachers also referred to the community-psychosocial factor that included awareness, values, and knowledge. According to the teachers, common preferences and values can influence whether a course of action is implemented or not. For example, one teacher [Z-06] mentioned the preference to eat a cooked meal and to be full rather than having a balanced diet. In addition, awareness about the necessity of certain courses of action plays an important role-predominantly because awareness is missing: "For example, one will build a WC, one will construct a shower. But often, the people don't care at all about this shower or about this WC" [M-05, 27-28] (Topic Clean water, sanitation, and hygiene). Furthermore, the relevance of shared knowledge was mentioned several times. One teacher specified that training is needed: "[Respecting the hygiene rules for genital organs] is possible to implement but it needs training" [AE-01, 110-112] (Clean water, sanitation, and hygiene). The same teacher perceived such training to be important to promote knowledge about how to correctly execute some courses of action. 


\subsubsection{Individual Level}

With $7.2 \%$ of all codings, the teachers only sometimes addressed the individual level when evaluating implementation possibilities. Most references included statements referring to the ease or difficulty of executing the courses of action (technological dimension), for example: "[Respecting the hygiene rules concerning water use] is easy to implement, there is nothing complicated about it" [Z-06, 173-174] (Topic Clean water, sanitation, and hygiene). Likewise, the use of a tippy-tap (a hands-free handwashing station) was considered easy to implement: "This is easy for the people to construct, be it in the city or in the village" [M-05, 173-174] (Topic Clean water, sanitation, and hygiene, technological dimension). Two teachers [Z-06, L-07] also mentioned the value of a course of action when food conservation does not always appear to be necessary: "One does not see [dried meat] in the city anymore because there is [fresh] meat every day" [Z-06, 211-212] (Topic Food hygiene and healthy diet, technological dimension). Furthermore, two teachers [AE-01, AH-02] referred to individual wealth (contextual dimension) as relevant for implementing a course of action, for instance, to avoid malnutrition: "In the city, it is difficult to implement. Difficult to implement because all this is to buy. If you don't have the money, you will not have it" [AH-02; 173-174] (Topic Food hygiene and healthy diet).

\subsubsection{Habitual Level}

The habitual level display $16.5 \%$ of all codings. Most statements referred to the psychosocial dimension and thus included existing habits that favor or hinder the implementation of the courses of action. For example, some people have their habits for the Prevention of (serious) illness: "There are those who go to the doctor and those who don't go there. They go to those that do, for example, the massage" [AE-01, 326-328]. Likewise, the teachers referred to daily habits (psychosocial dimension) for Clean water, sanitation, and hygiene: "[Storing treated water in reservoirs with solid cover] it is possible that they do it, the people in the village, but they live in the reality; they hardly cover it" [AE-01 168-169]. According to the teachers, the environment (contextual dimension) plays a role in implementation and habit formation, too, particularly regarding open defecation: "In the rural life, it is difficult to implement. [ ... ] because there are many places where one could do open defecation [...] [In the city, it is] easy to implement because they cannot defecate but only in the latrine" [AH-02 210-213] (Topic Clean water, sanitation, and hygiene). In the technological dimension, only one coding [M-05] appeared on the habitual level, referring to the effectiveness of routine tooth brushing to improve dental health.

\subsection{Relevant Factors for Implementing Land-Use Courses of Action}

Table 3 shows the general pattern of the coding distribution in the land-use context (RQ 2). As in the health context, the number of codings per topic differed: from 15 codings in Management of cultivations other than vanilla to 38 codings in Soil management.

In all three land-use topics, a great share of codings belonged to the individualtechnological factor referring to, for instance, the perceived cost or value of the land-use practice. Here, the number of codings was higher for the two management of cultivation topics (vanilla and other than vanilla) than for Soil management. In addition, the habitualpsychosocial factor had codings in all three land-use management topics. However, the topic Soil management displayed a larger share of habitual-psychosocial codings compared to the two management of cultivation topics. In addition, there were several codings on the community level; these community-related codings mostly referred to the contextual dimension, followed by the psychosocial dimension. Codings regarding the technological dimension are less present in the land-use context. Regarding Management of cultivations other than vanilla, only a few codings appeared in all three dimensions of the community level $(6.7 \%)$. With respect to the community level, most codings belong to the topics Management of vanilla cultivations and Soil management. The topic Management of cultivations other than vanilla is the only one with a considerable share of codings for the structuraltechnological factor. The latter referred to, for example, land-use products such as improved 
seeds or plants provided by the state. Only one coding belonged to the interpersonal level; it relates to the topic Management of cultivations other than vanilla. In sum, we identified relevant factors for implementing land-use courses of action on all five levels of the IBMWASH model.

Table 3. Distribution of codings per factor, based on the IBM-WASH model, as percentage for each of the three land-use topics and the complete land-use context. Percentages greater than 10.0 are bolded. The table includes unpublished results from Schneider [66].

\begin{tabular}{|c|c|c|c|c|c|}
\hline Level & Dimension & $\begin{array}{l}\text { Management } \\
\text { of Vanilla } \\
\text { Cultivations } \\
\text { (21 Codings) }\end{array}$ & $\begin{array}{l}\text { Management of } \\
\text { Cultivations Other } \\
\text { than Vanilla } \\
\text { (15 Codings) }\end{array}$ & $\begin{array}{l}\text { Soil } \\
\text { Management } \\
\text { (38 Codings) }\end{array}$ & $\begin{array}{l}\text { Land-Use } \\
\text { Context } \\
\text { (74 Codings) }\end{array}$ \\
\hline \multirow{3}{*}{$\begin{array}{l}\text { Structural/ } \\
\text { Societal }\end{array}$} & Contextual & 4.8 & 6.7 & 2.6 & 4.1 \\
\hline & Psychosocial & - & - & 2.6 & 1.4 \\
\hline & Technological & 4.8 & 13.3 & - & 4.1 \\
\hline \multirow{3}{*}{ Community } & Contextual & 23.8 & 6.7 & 23.7 & 20.3 \\
\hline & Psychosocial & 14.3 & 6.7 & 10.5 & 10.8 \\
\hline & Technological & - & 6.7 & 2.6 & 2.7 \\
\hline \multirow{3}{*}{$\begin{array}{l}\text { Interpersonal/ } \\
\text { Household }\end{array}$} & Contextual & - & 6.7 & - & 1.4 \\
\hline & Psychosocial & - & - & - & - \\
\hline & Technological & - & - & - & - \\
\hline \multirow{3}{*}{ Individual } & Contextual & - & - & - & - \\
\hline & Psychosocial & - & - & - & - \\
\hline & Technological & 28.6 & 33.3 & 21.1 & 25.7 \\
\hline \multirow{4}{*}{ Habitual } & Contextual & - & - & 5.3 & 2.7 \\
\hline & Psychosocial & 14.3 & 20.0 & 31.6 & 24.3 \\
\hline & Technological & 9.5 & - & - & 2.7 \\
\hline & & 100.0 & 100.0 & 100.0 & 100.0 \\
\hline
\end{tabular}

\subsubsection{Structural Level}

In total, $9.6 \%$ of all codings in the land-use context were associated with the structural level. According to the participants, the successful implementation of land-use courses of action can depend on climatic and ecological conditions, such as rainfall or harmful insects. Three participants mentioned this aspect in the contextual dimension, while each referred to a different one of the topics. One teacher [L-07] argued that agricultural associations and the state can support the implementation of courses of action by distributing trees, plants, and rice grains (both management of cultivation topics, technological dimension). Another teacher [M-05] mentioned the sacred woods as relevant for the choice of land to be cultivated and, thus, as a determinant for shorter fallow cycles influencing the soil quality (Topic Soil management, psychosocial dimension).

\subsubsection{Community Level}

Most codings in the land-use context belong to the community level (33.8\% of all codings). According to the teachers, some courses of action require specific resources for implementation (contextual dimension). Examples are a diversity of plants to cultivate, access to quality vanilla plants, and quality rice plants and seeds (both management of cultivation topics). The teachers considered access to these resources to be relevant. For example, planting diverse tutor trees is "easy to implement because there is jatropha and the gliricidia" [Z-06, 579-580] (Topic Management of vanilla cultivations, contextual dimension). Interestingly, many teachers named land scarcity as a limiting determinant for sustainable soil management: "This is impossible to implement because the land is insufficient" [AF-11, 346] (contextual dimension). Two teachers [AC-14, Y-02] mentioned that knowledge about correct implementation is missing: "[Fertilizing hill rice cultures] is difficult to implement! There, we don't know how to make compost" [Y-02, 479-481] (Topic Soil management, psychosocial dimension). One teacher [AC-14] explained several times that the possibility of implementing sustainable land use in all three topics depends on attitudes. For example, regarding 
Management of vanilla cultivations, this teacher said: "Because, like I said before, the people in the village are based on the cultivation. When they find advantages, it is easy for them to implement it" [AC-14, 661-662] (psychosocial dimension). Furthermore, two teachers [L-07, AH-02] mentioned access to specific products for cultivation, such as natural fertilizer, as relevant for Management of cultivations other than vanilla and Soil management (technological dimension).

\subsubsection{Individual Level}

On the individual level, with a quarter of all codings (25.7\%), only the factor of the technological dimension was addressed. Three teachers estimated the possibility of implementing a course of action depending on the ease or difficulty of executing it. For example, one teacher [Y-02] said it might be difficult to cut all invasive plants such as the big bamboo (Topic Management of cultivations other than vanilla). Furthermore, the teachers often connected the possibility of implementing to the benefits for agricultural revenue. For example, one teacher estimated the cultivation of other cash crops on vanilla cultivations as easy because "one can also have other products with the coffee and the cacao" [L-07, 408] (Management of vanilla cultivations). Conversely, two other teachers [M-05, AC-14] argued that it is difficult "because the vanilla likes to be in monoculture and if there are too many other plants that take the nutrients from the soil, [the vanilla] will be a bit late for its development" [M-05, 349-351]. Similar statements for the agronomic benefit also appeared with Soil management courses of action: "This is easy to implement, very easy to implement, because it brings advantages. [... ] This is what makes it easy to implement" [AC-14, 863, 867]. All the codings mentioned above belong to the technological dimension.

\subsubsection{Habitual Level}

Almost a third of all codings were under the habitual level (29.7\%). Teachers perceive existing land-use practices such as crop rotation, intercropping, and fertilization as highly relevant courses of action. These belong to the psychosocial dimension. On the one hand, teachers associated the courses of action with existing land-use practices that facilitate implementation. For example, one teacher explained that adapting the cultivation to the soil quality with crop rotation is easy to implement, "because there are already many different plantations that the farmers manage in the village" [L-07, 538-539] (Topic Soil management). On the other hand, the teachers mentioned common land-use practices that hinder implementation of primarily Soil management-related courses of action: "In the rural life, these courses of action are often inaccessible because they often do the slash-and-burn cultivation" [AE-01, 479-480]. Furthermore, one teacher argued that the adaptation to soil conditions is difficult because farmers act according to tradition. For example, they will use "the plants that they planted there since always" [AE-01, 859]. All the codings of land-use practices mentioned above belong to the habitual-psychosocial factor.

Regarding the technological dimension, only two teachers [AE-01, L-07] mentioned the effectiveness of routine implementation of the courses of action (Topic Management of vanilla cultivations). Furthermore, two teachers [AE-01, Y-02] referred to land scarcity as habitual-contextual factor. That leads to the permanent cultivation of land without sufficient soil recovery: "The fact that this is not easy is because the land is already scarce, so the people cannot let the vegetation develop naturally to do the cultivation afterwards. Yes, they cultivate this year and they still cultivate the next year, this is always like this" [Y-02, 287-290] (Topic Soil management, contextual dimension). Thus, land scarcity is described as a challenge for implementing sustainable soil management.

\subsection{Implementing Health and Land-Use Courses of Action-Differences in Factor Distributions}

In the following, we respond to RQ 3: "In which way do Malagasy primary teachers perceive that health- and land-use-related courses of action differ in their possibilities of implementation for ESD?" First, we focus on comparing the coding distribution regarding health- and land-use-related courses of action through the levels of the IBM-WASH model. Second, we conduct the same comparisons through dimensions of the model. 
In the following, we compare each one of the 15 factors in the health context with its percentage (right-hand column of Table 2 "health context" with 194 codings that total 100\%) to the corresponding factor in the land-use context (right-hand column of Table 3 with 74 codings that total $100 \%)$. Using this approach, we can compare the general distribution patterns of codings and answer RQ 3.

\subsubsection{Comparison of Health and Land-Use Topics by Levels}

In both contexts, the habitual-psychosocial factor showed a high number of codings with a greater share in the land-use than the health context (health: $12.9 \%$ in Table 2; land use: $24.3 \%$ in Table 3). An inverse picture is given for the community-contextual factor distribution referring to, for example, the built environment and infrastructure (health: $36.1 \%$; land use: $20.3 \%$ ) and the community-psychosocial factor referring to, for example, shared knowledge, attitudes, and awareness (health: 13.9\%; land use: $10.8 \%$ ). However, regarding the community-technological factor, a considerable share of codings only occurred in the health context (health: $21.1 \%$; land use: $2.7 \%$ ). Both contexts showed similar overall distribution patterns of codings regarding the interpersonal level and the structural level. On the interpersonal level, referencing aspects such as gender roles and social norms, (almost) no codings appeared in either context. On structural level, referring to, for example, policies, ecology, or culture, only a few codings appeared. The most striking contrast between the distributions of codings in the health and the land-use contexts was for the individual level regarding the technological dimension. While only a few codings appeared in the health context (6.2\% in Table 2), the individual-technological factor seemed to be more relevant to the land-use context ( $25.7 \%$ in Table 3$)$.

\subsubsection{Comparison of Health and Land-Use Topics by Dimensions}

Changing the perspectives and comparing only the distributions per dimension of the IBM-WASH model delivered a further interesting pattern (Tables 4 and 5).

Table 4. Distribution in percent of codings per dimension of the IBM-WASH model for the four health topics and all four topics together (health context). The highest percentage per topic and context are bolded.

\begin{tabular}{cccccc}
\hline Dimension & $\begin{array}{c}\text { Clean Water, } \\
\text { Sanitation, and } \\
\text { Hygiene } \\
\text { (94 Codings) }\end{array}$ & $\begin{array}{c}\text { Food } \\
\text { Hygiene } \\
\text { and } \\
\text { Healthy Diet } \\
\text { (37 Codings) }\end{array}$ & $\begin{array}{c}\text { Prevention of } \\
\text { (Serious) } \\
\text { Illness } \\
\text { (34 Codings) }\end{array}$ & $\begin{array}{c}\text { Risk } \\
\text { Avoidance } \\
\text { (29 Codings) }\end{array}$ & $\begin{array}{c}\text { Health } \\
\text { Context } \\
\text { (194 Codings) }\end{array}$ \\
\hline Contextual & $\mathbf{4 1 . 5}$ & $\mathbf{4 0 . 5}$ & $\mathbf{3 5 . 3}$ & $\mathbf{5 1 . 7}$ & $\mathbf{4 1 . 8}$ \\
Psychosocial & 28.7 & 27.0 & 29.4 & 31.0 & 26.8 \\
Technological & 29.8 & 32.4 & 35.3 & 1.0 & 31.4 \\
\hline & 100.00 & 100.00 & 100.00 & 100.00 & 100.00 \\
\hline
\end{tabular}

Table 5. Distribution in percent of codings per dimension of the IBM-WASH model for the three land-use topics and all three topics together (land-use context). The highest percentage per topic and context are bolded.

\begin{tabular}{ccccc}
\hline Dimension & $\begin{array}{c}\text { Management } \\
\text { of Vanilla } \\
\text { Cultivations } \\
\text { (21 Codings) }\end{array}$ & $\begin{array}{c}\text { Management } \\
\text { of } \\
\text { Cultivations other than } \\
\text { Vanilla } \\
\text { (15 Codings) }\end{array}$ & $\begin{array}{c}\text { Soil } \\
\text { Management } \\
\text { (38 Codings) }\end{array}$ & $\begin{array}{c}\text { Land-use } \\
\text { Context } \\
\text { (74 Codings) }\end{array}$ \\
\hline Contextual & 28.6 & 20.0 & 31.6 & 28.4 \\
Psychosocial & 28.6 & 26.7 & 44.7 & 36.5 \\
Technological & $\mathbf{4 2 . 9}$ & 53.3 & 23.7 & 35.1 \\
\hline & 100.00 & 100.00 & 100.00 & 100.00 \\
\hline
\end{tabular}


In the health context (Table 4), across all four topics, most codings were associated with the contextual dimension $(41.8 \%)$. They refer to the setting of implementation. Regarding single topics, only the topic Prevention of (serious) illness showed as many codings in the technological as in the contextual dimension (both 35.3\%). The technological dimension refers to the products needed for the course of action, such as soap or toothpaste, or to the evaluation of the course of action itself (such as strengths and weaknesses). In the other three topics of the health context, the technological dimension was the second most relevant one with approximately one-third of the codings (29.8-32.0\%).

Regarding all four topics together in the technological dimension, the share was $31.4 \%$. In contrast, the psychosocial dimension (shared attitudes, knowledge, habits) showed the fewest codings of the three dimensions (26.8\%; Table 4$)$.

In the land-use context, the distribution of codings in the three dimensions did not show a consistent pattern across topics. In the two management of cultivation topics, the highest share of codings was associated with the technological dimension (42.9\% and $53.3 \%$; Table 5). In contrast, most codings in the topic Soil management appeared within the psychosocial dimension (44.7\%); here, the technological dimension had barely one quarter of codings, which was the lowest share.

Comparing the share of codings in the column "Land-use Context", the psychosocial dimension has the highest one $(36.5 \%)$, closely followed by the technological dimension (35.1\%). Here, the contextual dimension has the lowest share $(28.4 \%)$.

\section{Discussion}

In the present study, we analyzed factors relevant for the implementation of health and land-use courses of action. Getting to know such factors is crucial for facilitating sustainable health behavior and sustainable land-use decisions through regionally adapted ESD [14,41].

For the analysis, we used the IBM-WASH model, which was originally established for qualitative analyses of WASH behavior. We successfully applied it to a broader health context, and we newly applied it in a land-use context, with respective adaptations (Table 1). Before reviewing the results for RQs 1-3, we will shed light on the suitability of applying the IBM-WASH model in our study. The application in the land-use context represents an innovation in educational research and research on land-use decisions. During data analysis, no obstacles occurred that are specifically related to a land-use context.

In sum, the IBM-WASH model turned out to be generally suitable. It covered all perspectives that were mentioned by the teachers. However, only a few codings addressed the interpersonal level. One reason for this could be that we inductively extended the contextual dimension on the community level by the aspect "general available arable land" (Table 1) - an aspect that is defined as "available space" on the interpersonal level in the original model [14]. The definition "general available land" showed a better fit with our study material as teachers often referred to a general land scarcity. Interestingly, gender roles were not explicitly mentioned. That might be another reason for the low number of codings on the interpersonal level. However, we decided not to combine the interpersonal with the individual level, as was done by McMichael and Robinson [50]. We considered the low number of codings on the interpersonal level to be an interesting result because aspects on the interpersonal level, such as gender roles and conformity with social norms, were relevant for improved health behavior in previous studies $[29,48,55,57]$. It was surprising that such references were largely missing from our think-aloud protocols.

It was not always possible to clearly distinguish which factors are perceived as challenges and which are perceived as opportunities. On the one hand, this results from the multitude of different aspects that can be covered by one factor (e.g., the communitycontextual factor; Table 1). While most teachers considered general available space to be a hindrance to implementing land-use courses of action, the access to resources was sometimes considered an opportunity. Furthermore, different socioeconomic situations among the teachers might have led to different associations regarding the implementation 
of a course of action. For example, some teachers considered the possibilities for implementing a healthy diet in the village by introducing a variety of fruits and vegetables as easy because people can grow the products themselves (community-contextual factor). In contrast, others considered the healthy diet difficult to implement in the rural areas, as there is only restricted access to a market (community-contextual factor).

In addition, the different perceptions of the teachers on the identified factors can result from different conditions in the villages and cities they work in. For example, the infrastructure (community-contextual factor) can differ between villages. It can be a challenge in one village and an opportunity in another village.

The only factor that was clearly perceived as an opportunity in the health and land-use contexts was the structural-technological factor, referring to the promotion or distribution of a product. All corresponding codings clearly referred to increased possibility for implementing a course of action if the state or an organization promoted it. This accounts, for instance, for the distribution of mosquito nets or the provision of training.

The different teacher perspectives indicated that whether factors are perceived as opportunities or as challenges depends on the teachers' school setting. For example, access to markets and resources, existing habits, prevalent attitudes in the community, or the socioeconomic situation of the participating teachers, including their general wealth and dependence on natural resources, can come into play.

Nonetheless, the data contribute to knowledge gains with regard to which factors must be considered for regional and local ESD teaching, even if the classification as opportunity or challenge may differ according to the local context.

In the analytical process, we confirmed the interconnectedness and overlapping of different factors mentioned in other studies applying the IBM-WASH model [56-58]. For example, associations with the built and physical environment (contextual dimension) could be at the community level or, if connected to habits or routines, at the habitual level (e.g., nearby existing latrines to promote their routine use). A further example is the differentiation between access to the market (community-contextual factor) and access to a product (community-technological factor), which was, in some cases, difficult to clarify. To clearly distinguish between these factors, we only considered a statement to be a technological factor if the teacher referred to the accessibility or presence of a specific product that is indispensable for implementing the course of action (Table 1, Table A2 in Appendix B). Despite these difficulties, we were able to define a coding system that allowed for a transparent qualitative analysis of the think-aloud protocols for both the health and the land-use context (Table A2 in Appendix B).

\subsection{Context, Setting, and Existing Habits Are Relevant for Implementing Health Courses of Action}

The distribution of codings in the health context allowed for valuable insights into teacher perceptions regarding the implementation of courses of action and underpinning factors of the IBM-WASH model (see results of RQ 1 in Section 3.1).

The prevalence of codings belonging to the community level was striking (Table 2). The community level refers to "the physical and social environment in which individuals are nested" [14], p. 6. Our results confirm previous study findings demonstrating the relevance of the community level for improved health behavior: regarding the contextual dimension on the community level, it turned out that health behavior was highly dependent on access to markets and resources [44,56]. Likewise, access to specific products representing the technological dimension and necessary for the intended behavior can be crucial on the community level [49,51]. Regarding the psychosocial dimension, the important role of shared knowledge, attitudes, and values for improved health behavior (in the present study coded as a community level factor) has been highlighted in previous research [44,47,51,56-58]. However, in the present study, the relevance of the communitypsychosocial factor only minimally applied to the topic Risk avoidance (Table 2). The courses of action in this topic referred, rather, to actions in a globalized world, such as traffic behavior, protection from pesticides and polluted air, and waste disposal. It is probable that 
these health-promoting courses of action are not yet well established in communities. Thus, it is plausible to have a reduced number of codings in the community-psychosocial factor.

Furthermore, the prevalence of the habitual-psychosocial factor in the health context across all four topics (Table 2) is plausible, given that existing habits have a strong influence on the implementation of desired behavior [14,29]. Improved health behaviors "are not one-time behavior changes-they require significant repetition across both time and space" [14], p. 5.

Interestingly, the topic Prevention of (serious) illness was the only topic with codings on the structural-technological factor (Table 2). The courses of action in this topic refer to malaria prevention, doctor consultation, and following the health care provided through schools. The high number of codings for the structural-technological factor can be explained by the state's interventions regarding health promotion in schools [7] and the distribution of free impregnated mosquito nets [31]. This result highlights that interventions on a policy level can be a cost-effective means of improving health behavior [69].

Discussing the distribution of codings across the three dimensions of the IBM-WASH model, it is evident that most codings appear in the contextual dimension (Table 4). This is intriguing, given that many other models that focused on improved health behavior did not consider the contextual dimension [14]. In the IBM-WASH model, the contextual dimension comprises "determinants related to the individual, setting, and/or environment that can influence behavior change and adoption of new technologies" [14], p. 6. The relevance of the contextual dimension for improved health behavior has been highlighted in previous studies. They revealed, for example, that access to water [44,52] and environmental constraints (i.e., for latrine construction) [50,58] on a community level, along with cost barriers (i.e., for buying soap and chlorine) $[52,53]$ on an individual level were highly relevant for implementation of the desired behavior. Further studies have indicated that gender and educational status (interpersonal level) were relevant contextual determinants for the intended behavior in the investigated field [48,57]. However, in the present study, gender and educational status were not mentioned. This can be explained by our questionnaire: it includes courses of action that are rather general and do not refer to a specific group of people (i.e., by gender or educational status). In return, the participants mentioned the infrastructure (coded as community-contextual factor), such as distance to health centers or traffic density, as relevant determinants that were not explicitly considered in prior studies. Again, this can be explained by the focus of our questionnaire. While previous studies applying the IBM-WASH model focus on WASH practices (Table A1 in Appendix A), our study address a broad range of different health and land-use topics. Therefore, it could be that the teachers mentioned aspects that were not considered in previous studies.

To sum up, the teachers considered community-level factors (e.g., access to markets and products or shared attitudes, values, and knowledge) along with existing habits to be particularly relevant for implementing health courses of action. Furthermore, the contextual dimension (e.g., access to resources, infrastructure, and wealth) plays a crucial role in the health context. The implications of these findings for regionally relevant ESD regarding health are discussed in Section 4.4.

\subsection{Setting, Cost-Benefit Relations, and Existing Habits Are Relevant for Implementing Land-Use Courses of Action}

As in the health context, the distribution of codings of teacher perceptions in the landuse context revealed an interesting pattern of addressed factors of the IBM-WASH model that are relevant for implementing courses of action (see results for RQ 2 in Section 3.2).

The community-contextual and the community-psychosocial factor are relevant for the implementation of the courses of action for Management of vanilla cultivations and Soil management (Table 3). This corresponds to the prevalence of community-level factors in the health context, where access to markets and specific products are relevant. In addition, teachers often mentioned land scarcity (community-contextual factor) with relevance for the implementation of sustainable soil management. Soil management courses of action refer to general soil management practices in vanilla plantations, rice plantations, as well 
as general arable land, such as crop rotation, fertilization, and natural soil recovery. The fact that these practices were connected to land scarcity is plausible, as land scarcity is a common global land-use challenge [70]. It also appears in northeast Madagascar [9] and has likewise been mentioned by experts in the SAVA region in a preceding Delphi study [10]. In contrast to the Management of vanilla cultivations and Soil management, the implementation of courses of action regarding the Management of cultivations other than vanilla does not seem to depend on community level-related factors. Corresponding courses of action refer to rice production and the cultivation of small house gardens. In the SAVA region, rice is predominantly cultivated for self-provision [39]. Thus, corresponding land-use decisions are closely connected to personal needs. This might explain that the codings regarding Management of cultivations other than vanilla were rather located on the individual and habitual than on community level.

In the land-use context, the individual-technological factor-referring to strengths and weaknesses of the course of action such as perceived cost, value, and convenienceappeared to be the most important. Many teachers made connections between the perceived cost-benefit relation of a course of action for cultivation and soil managements and the possibilities for implementation. This is plausible, as most people in Madagascar have a low living income. They orient their land-use decisions towards the satisfaction of their basic needs [41,71]. For example, farmers in northeast Madagascar are aware of the relevance of forests and the ecosystem services they provide [8]. However, their ability to adapt their farming strategies to increase forest conservation is restricted by their vulnerability and risk aversion [8,41]. Thus, the perceived cost-benefit relation of the courses of action, as coded with the individual-technological factor, appears to be highly relevant for implementation.

As in the health context, the habitual-psychosocial factor that refers to existing habits and practices is relevant for implementing land-use courses of action. This applies to all land-use topics, however, with different shares of codings per topic (Table 3). The lower share of codings in Management of vanilla cultivations compared to the two other topics can be explained by the medium age of most vanilla plantations. Vanilla was introduced as a cash crop into the study region already in 1870 [72]. However, in 2018, the medium age of a vanilla plantation was 15 years [33], indicating that many farmers only began vanilla cultivation a few decades ago or even later. Thus, existing practices regarding vanilla cultivation might not be well established yet. This reduces the relevance of habits and existing practices. In contrast, the topic Soil management showed the highest share of codings referring to existing practices (habitual-psychosocial factor). Four of the nine Soil management courses of action refer to hill rice production. Farmers in the SAVA region often practice hill rice production as slash-and-burn agriculture for self-provision [39]. The reasons for applying the destructive practice despite numerous policy interventions promoting alternatives are not yet fully understood [39]. However, social and traditional determinants play an important role [39]. This might explain the high number of Soil management codings regarding the habitual-psychosocial factor (Table 3).

The distribution of codings in the land-use context across the three dimensions of the IBM-WASH model gives further insights into the relevant determinants for implementing land-use courses of action (Table 5). The prevalence of the psychosocial dimension for Soil management is striking. It can be explained by the high number of Soil management codings regarding the habitual-psychosocial factor, referring to existing practices (Table 3). For the two management of cultivation topics, the prevalence of the technological dimension results from the high number of codings regarding the individual-technological factor (Table 3). This factor refers to strengths and weaknesses of the courses of action that many teachers connected to cost-benefit relations. Thus, the prevalence of the technological dimension compared to the other two dimensions highlights the relevance of a positive cost-benefit evaluation of the courses of action.

In summary, the teachers particularly mentioned community-level factors (e.g., available arable land, access to markets, or shared knowledge), strengths and weaknesses of land-use courses of action (individual-technological factor), and existing habits when esti- 
mating the possibility of implementation. The implications of these findings for regionally relevant ESD regarding land use are discussed in Section 4.4.

\subsection{Differences in the Possibility of Implementation of Health- and Land-Use-Related Courses of Action}

For the analysis of factors that the teachers perceived to be relevant for implementing health and land-use courses of action, we applied the same adapted coding system based on the IBM-WASH model (Table 1). This allowed a closer look at the similarities and differences of the distribution of codings in both contexts-health and land use (see the results for RQ 3 in Section 3.3).

The general comparison of both contexts revealed some similarities, such as few codings on the structural and interpersonal levels and many codings on (i) the communitycontextual factor, (ii) the community-psychosocial factor, and (iii) the habitual-psychosocial factor. The three factors with many codings point to their consideration for regionally adapted ESD teaching (Section 4.4). However, a closer look at the data behind the codings of the community-contextual factor revealed interesting differences. Regarding the community-contextual factor in the land-use context, teacher statements predominantly referred to general available arable land and access to resources (Section 3.2.2). While the access to resources was also mentioned in the health context, the teachers likewise considered infrastructure and general wealth as relevant community-contextual factor for implementing the health courses of action (Section 3.1.2). The differences of the various aspects that lie behind the community-contextual factor indicated that recommendations for regional ESD teaching cannot be applied to both contexts. Thus, implications for ESD should be considered separated by context. This allows for careful adaptation of the teaching content to regional conditions.

The most striking difference between the coding distributions in both health and land-use contexts was the prevalence of the individual-technological factor in the land-use context. This factor refers to the strengths and weaknesses of a course of action. It is less relevant in the health context. The difference in prevalence mentioned above might be due to the nature of the health and the land-use courses of action. While those in the health context rather refer to daily life practices, those of the land-use context comprise practices that require more time and effort. For instance, they need a more conscious decision with an evaluation of (perceived) cost, values, and convenience [10].

Despite the differences between the health and the land-use courses of action, we successfully applied the adapted IBM-WASH model for both contexts. Therefore, the results can encourage future research into using the model with different ESD topics to identify factors that need to be considered for ESD.

\subsection{Implications for Education and Training Regarding Health and Land Use}

The present study points out the distribution of codings of teacher perspectives on implementing health and land-use courses of action. Based on these findings, we are able to provide recommendations for designing a regionally relevant ESD for teacher and school education.

Regarding health education, considering the community level within all three dimensions, but particularly the contextual dimension, is important. As a result, teaching health topics requires an adaptation of the teaching content to fit several circumstances. Among them are the local environment of the school (community-contextual factor), the accessibility of products needed for courses of action (community-technological factor), and the knowledge and attitudes that are prevalent in the community where the school is located (community-psychosocial factor). This implies, for example, where to find the next water source and whether it has drinking water quality (e.g., river, community tap, well), where to buy specific products (e.g., soap, chlorine, new underwear, protective clothing), and where to find the next health center and how much it costs to go there.

Considering such determinants for improved health behavior is highly relevant in teaching. Local conditions (e.g., access to products, resources, infrastructure) strongly differ 
between not only rural and urban areas [28,73] but also between different communities within urban and within rural areas (personal observation). Furthermore, existing habits likewise play a crucial role in implementing the health courses of action. Thus, health teaching should also take up health habits that already appear in the community. For example, persons who already integrate health-conscious behavior into their daily routines can be identified as role models. In contrast, health teaching can detect "bad" existing habits (e.g., open defecation) and uncover how these are negatively affecting health. In addition, existing health-conscious habits that have already proved to be easy to implement within a community (e.g., water boiling instead of chlorination for preparing drinking water cf. [74]) can serve as examples.

Regarding land-use education, similar to health education, the community level is of high importance. Here, the community level largely referred to available arable land, shared knowledge, or access to markets and products. Therefore, teaching content regarding sustainable land use should consider the environment near the community where the school is located. This applies, among other things, to the availability of arable land, local environmental problems [75], locally cultivated products, such as vanilla [74], and local narratives and stories related to environmental protection [74].

Furthermore, land-use education should take into account existing habits related to land use, including the land-use practices that are common around the community where the school is located. Even if the possibilities to change these habits are limited, the willingness to change is crucial for sustainable development [41].

The technological dimension, considering perceived cost, value, or convenience of courses of action, was the most relevant for the two management of cultivation topics. Many teachers referred to cost-benefit relations. Therefore, land-use teaching should emphasize it. Social and economic perspectives can be more important for the local population compared to the environmental one [19,71]. Thus, integrating cost-benefit relations of sustainable land-use practices in teaching can increase the regional relevance of ESD.

In our quantitative study on teacher procedural knowledge, teachers in rural schools, in particular, had land-use knowledge; they could use such knowledge for ESD teaching [11]. Many participants of the present study further demonstrated their insights into land-use activities. As previous research indicates that many teachers also cultivate vanilla [76], their land-use knowledge and their insights into land-use activities are presumably based on experience. Teachers should be encouraged to integrate such experiences when teaching topics of sustainable land use and related benefits for the environment.

Interestingly, in both contexts-health and land use-teachers mentioned training and workshops as relevant determinants for implementing the courses of action. However, none of the teachers referred to their own role as multipliers of knowledge. They did not explicitly state that they have the ability to influence the behavior of schoolchildren regarding health or land use. Thus, even if teachers in Madagascar see themselves as role models for the society in general [77], their key role for sustainable development does not seem to be evident to them. One core task is to empower (prospective) teachers to support their pupils to develop themselves towards future change agents in contributing to sustainable development.

\subsection{Limitations}

When interpreting the results, it has to be considered that only 10 different teachers took part in our study. However, the teachers come from cities and villages in the four different districts of the SAVA region (Section 2.3). Therefore, perspectives from different rural and urban settings are covered by the study sample. They allowed for differentiated insights into regional possibilities for implementing health and land-use courses of action.

However, we did not systematically check whether the teacher perspectives are accurate or if potential misconceptions occurred. The systematic comparison with qualitative data from the previous expert study [10] was not applicable. The reason is that the teachers mentioned aspects that did not occur in the expert study. Furthermore, the conditions 
for implementing the health and land-use courses of action may vary in different villages and cities.

In any case, the data from the present study are not meant to be used for giving recommendations for specific teaching content. It focuses on teacher perspectives of implementation possibilities for ESD-relevant courses of action. The theory-driven coding of the teacher perspectives allowed for identifying general factors according to the IBM-WASH model. These included implementation opportunities and challenges-important for the regionally relevant teaching of health and land-use topics. Therefore, the present study provides valuable information on its own on teachers-key players in the educational system. Thus, the knowledge gained in this study is complementary to the recommendations on health and land-use topics for ESD teaching concluded from analyzing experts' data in a previous study [10].

Regarding the comparison of the health and the land-use context, the different questionnaire structure of both contexts needs to be taken into account (see result Section 3.3). While the health courses of action were estimated twice regarding the possibility of implementation (for urban and rural life), the land-use courses of action were only estimated once regarding the possibility of implementation in rural life. This results in a considerably lower number of codings in the land-use context (74 codings) compared to the health context (194 codings). Therefore, one single coding in the land-use context has more influence on the distribution of codings (displayed as percentage) in topics with a low number of codings, e.g., in Management of cultivations other than vanilla with 15 (out of the 74) codings, compared to topics with a high number of codings in the health context, e.g., Consideration of clean water, sanitation, and hygiene with 94 (out of the 194) codings.

A further limitation is the low intercoder reliability [68] of only $62.3 \%$. However, consistent qualitative coding with all 15 factors of the IBM-WASH model has likewise been challenging in previous studies. This is due to the conceptualization, as the factors are interconnected and show overlaps [56-58]. Therefore, some researchers report that they did not differentiate between different levels. For example, Tamene and Afework [57] merged the individual-level with the structural-level factors in the psychosocial and the technological dimension. In contrast, we already decided in an early stage of the analysis to stick to all 15 factors of the IBM-WASH model to create a differentiated picture of all 3 dimensions combined with all 5 levels.

A further aspect influencing the intercoder reliability is the two coders' different perspectives on the study material. While one coder has conducted quantitative and qualitative research in Madagascar, the second coder does not have an equal on-site experience. The second coder was not involved in data collection in Madagascar. These different perspectives enriched the analytic process and the discussion of different codings and thereby contributed to the analysis's quality [78]. Despite coding differences between the two coders, they found agreements for assigning nearly all coding units of the data set to one of the 15 factors of the IBM-WASH model. For few cases of disagreement, the codings were discussed within a group of four biology education researchers, with two of the researchers having on-site research experience in the SAVA region. Finally, this allowed a precise coding of teacher perspectives regarding implementation possibilities of health and land-use courses of action.

\section{Conclusions}

Promoting health and sustainable land use within the scope of the SDGs requires the consideration of multiple factors that influence sustainable health behavior and sustainable land-use decisions [14,41]. Accordingly, health and land-use education regarding ESD benefit from considering the gained insights into the relevant factors influencing the possibilities for implementation within teaching and learning.

To the best of the authors' knowledge, the present study is the first application of the IBM-WASH model in a broad context for gaining knowledge on possibilities for the implementation of courses of action in different topics of health and land use. Therefore, 
the study speaks for the huge potential of the IBM-WASH model to be utilized for future research regarding sustainable development, beyond the WASH focus, and even beyond a health context.

As previous research suggests, an interplay of multiple factors on different levels and different dimensions of the IBM-WASH model influences the implementation of health and land-use courses of action. The present study disentangles these different factors and gives insights into regional and local perspectives for implementing the ESD courses of action. Based on these results, we are able to inform the reorientation of primary school curricula and teacher education towards an ESD that is adapted to the regional and local realities of the learners.

Health education can benefit from considering the local context as well as the psychosocial and technological factors in the community of the school. Furthermore, health education should refer to habits that are prevalent in the community. Likewise, land-use education should consider community-level factors as well as existing land-use practices. To increase the relevance for the learners, cost-benefit relations of sustainable land use should be highlighted in land-use-related teaching and learning.

Regarding most factors mentioned by the teachers, they could not be consistently defined either as an opportunity or as a challenge. Depending on the location of the school where the teachers work (e.g., access to markets, products, resources, or infrastructure), existing habits or the perceived benefit of a course of action differed. Thus, opportunities and challenges for improved health behavior and sustainable land-use decisions depend on the community and the school's surroundings. The results on different teacher perceptions within the SAVA region speak for a flexible connection of the teaching content to the communities where the schools are located, cf. [6].

In the past years, the need for a regional adaptation of Malagasy school curricula has been highlighted several times to make education more relevant for the learners $[12,17,75]$. For ESD teaching, the UNESCO furthermore suggests to closely link the teaching to specificities of local communities [6]. The results of the present study are in line with the suggestions by UNESCO. We argue not only for a regional adaptation of school curricula but furthermore for an adaptation of the teaching content to the local school surroundings. Therefore, teachers should be equipped with the competencies they need to flexibly interpret the school curricula to integrate local realities of the scholar environment. Thereby, regionally relevant ESD can be viable, considering the regional specificities of the diverse regions in Madagascar. In addition, ESD benefits from taking into account the individual surroundings of the schools, such as infrastructure, access to resources, markets, and products, as well as prevalent values, attitudes, and existing habits within the community.

In sum, the present study gives differentiated insights into teacher perspectives on determinants for implementing health and land-use courses of action, e.g., also for NGOs. It provides insights into teaching conditions of health and land-use topics. We identified relevant factors important for regionally relevant ESD [10]. The teachers' perspectives represent crucial teaching and learning prerequisites for ESD in Madagascar [11].

Previous literature on land use and forest conservation in Madagascar explicitly requested interdisciplinary approaches for understanding "local land use, motivations and cost-benefit relations" [79], p. 92. In the present study, the IBM-WASH model turned out to be suitable for analyzing factors for implementing courses of action regarding sustainable land use. Therefore, the present study speaks for the application of the IBM-WASH model in land-use settings. It turned out to be a valuable approach for understanding the multiple factors influencing land-use decisions-taking into account the multi-level and multidimensional characteristics of the model. Therefore, the IBM-WASH model represents a promising tool for future studies regarding health, sustainable land use, and further contexts of ESD teaching and learning conditions.

Author Contributions: Conceptualization: J.N. and S.B.; methodology: J.N. and S.B.; formal analysis: J.N.; investigation: J.N.; writing—original draft preparation: J.N.; writing—review and editing: S.B.; 
visualization: J.N.; supervision: S.B.; project administration: J.N. and S.B.; funding acquisition: S.B. All authors have read and agreed to the published version of the manuscript.

Funding: We appreciate the financial support by the "Niedersächsisches Vorab" of Volkswagen Foundation (grant number: 11-76251-99-35/13 (ZN3119)).

Institutional Review Board Statement: The study was conducted in accordance with all relevant requirements of the Declaration of Helsinki. We discussed the institutional review board statement at length with the Sustainability Editorial Office.

Informed Consent Statement: Informed consent was obtained from all subjects involved in the study.

Data Availability Statement: The data cannot be shared at this time, as further analysis is awaited.

Acknowledgments: We are very grateful to Rebecca Schneider. Her unpublished Master's thesis [66] greatly contributes to the results presented here. We thank the local assistants for the data collection, transcription, and translation of the think-aloud recordings. We are grateful for the teachers who dedicated their time. A special thanks goes to Lisa Richter-Beuschel for contributing to the methodology and discussion of the final codings. This publication was supported financially by the Open Access Grant Program of the German Research Foundation (DFG) and the Open Access Publication Fund of the University of Göttingen.

Conflicts of Interest: The authors declare no conflict of interest.

\section{Appendix A}

Table A1. Literature review on qualitative and quantitative studies using the IBM-WASH model. (Remark regarding column "Type of Study and Sample Size": black: using the IBM-WASH model, grey: complementary data collection).

\begin{tabular}{|c|c|c|c|c|}
\hline Authors & Country & Scope & $\begin{array}{l}\text { Type of Study and } \\
\text { Sample Size }\end{array}$ & $\begin{array}{l}\text { Data Analysis } \\
\text { Related to } \\
\text { IBM-WASH Model }\end{array}$ \\
\hline \multicolumn{5}{|c|}{ Studies conducted in sub-Saharan Africa } \\
\hline $\begin{array}{c}\text { Seimetz et al. } 2016 \\
\text { [56] }\end{array}$ & Burundi & $\begin{array}{c}\text { Exploration of how contextual } \\
\text { and psychosocial factors affect } \\
\text { handwashing practices }\end{array}$ & $\begin{array}{l}671 \text { structured } \\
\text { interviews }\end{array}$ & $\begin{array}{l}\text { Hierarchical regression analysis; only } \\
\text { considering psychosocial factors } \\
\text { after the RANAS model of behavior } \\
\text { change [42] and contextual factors of } \\
\text { the IBM-WASH model (not } \\
\text { differentiating between levels) }\end{array}$ \\
\hline $\begin{array}{c}\text { Alemu et al. } 2017 \\
\text { [58] }\end{array}$ & Ethiopia & $\begin{array}{l}\text { Analysis of barriers to sustained } \\
\text { latrine adoption }\end{array}$ & $\begin{array}{l}8 \text { focus group discussions } \\
(n=75) ; \\
6 \text { in-depth interviews; } \\
4 \text { key informant } \\
\text { interviews }\end{array}$ & $\begin{array}{l}\text { Thematic coding; categories were } \\
\text { examined to determine if they fit into } \\
\text { the socioecological model [80] or the } \\
\text { IBM-WASH model }\end{array}$ \\
\hline $\begin{array}{c}\text { Tamene \& } \\
\text { Afework } 2021 \\
{[57]}\end{array}$ & Ethiopia & $\begin{array}{l}\text { Identification of barriers } \\
\text { to sustained latrine adoption }\end{array}$ & $\begin{array}{l}15 \text { focus group discussions } \\
(n=105) ; \\
10 \text { key informant } \\
\text { interviews }\end{array}$ & $\begin{array}{l}\text { Thematic coding; initial codes were } \\
\text { organized into the } 15 \text { factors of the } \\
\text { IBM-WASH model }\end{array}$ \\
\hline \multicolumn{5}{|c|}{ Studies conducted in South Asia } \\
\hline $\begin{array}{l}\text { Hulland et al. } 2013 \\
\text { [44] }\end{array}$ & Bangladesh & $\begin{array}{l}\text { Identification of an appropriate } \\
\text { handwashing station design; } \\
\text { development and revision of } \\
\text { IBM-WASH model }\end{array}$ & $\begin{array}{l}\text { ca. } 430 \text { semi-structured } \\
\text { interviews }\end{array}$ & $\begin{array}{c}\text { Thematic coding informed by the } 15 \\
\text { factors of the } \\
\text { IBM-WASH model }\end{array}$ \\
\hline $\begin{array}{c}\text { McMichael \& } \\
\text { Robinson } 2016 \\
\text { [50] }\end{array}$ & Nepal & $\begin{array}{c}\text { Evaluation of a } \\
\text { WASH-intervention combining } \\
\text { different approaches (e.g., } \\
\text { provision of hardware, } \\
\text { education); focus on drivers and } \\
\text { barriers to handwashing with } \\
\text { soap/ash and elimination of } \\
\text { open defecation }\end{array}$ & $\begin{array}{l}13 \text { focus group discussions } \\
(n=71) ; \\
29 \text { in-depth interviews; } \\
12 \text { key informant } \\
\text { interviews; } \\
90 \text { household observations }\end{array}$ & $\begin{array}{l}\text { Thematic coding informed } \\
\text { by the } 15 \text { factors of the } \\
\text { IBM-WASH model }\end{array}$ \\
\hline $\begin{array}{c}\text { Sultana et al. } 2018 \\
\text { [45] }\end{array}$ & Bangladesh & $\begin{array}{c}\text { Evaluation of the acceptability } \\
\text { and feasibility of a } \\
\text { shared handwashing } \\
\text { intervention }\end{array}$ & $\begin{array}{l}30 \text { in-depth interviews; } \\
5 \text { focus group discussions } \\
\quad(n=40)\end{array}$ & $\begin{array}{l}\text { Qualitative coding (inductive and } \\
\text { deductive categories), deductive } \\
\text { categories based on the three } \\
\text { dimensions of the IBM-WASH model } \\
\text { (not differentiating between levels) }\end{array}$ \\
\hline
\end{tabular}


Table A1. Cont.

\begin{tabular}{|c|c|c|c|c|}
\hline Authors & Country & Scope & $\begin{array}{l}\text { Type of Study and } \\
\text { Sample Size }\end{array}$ & $\begin{array}{l}\text { Data Analysis } \\
\text { Related to } \\
\text { IBM-WASH Model }\end{array}$ \\
\hline $\begin{array}{l}\text { Najnin et al. } 2015 \\
\text { [47] }\end{array}$ & Bangladesh & $\begin{array}{l}\text { Assessment of sustained } \\
\text { siphon filter usage }\end{array}$ & $\begin{array}{l}\text { Structured questionnaire } \\
\text { with } 755 \text { households and } \\
744 \text { neighbors; } \\
11 \text { in-depth interviews; } \\
15 \text { informants for } \\
2 \text { group discussions }\end{array}$ & $\begin{array}{l}\text { Thematic coding; } \\
\text { application of the IBM-WASH model } \\
\text { to the identified codes }\end{array}$ \\
\hline $\begin{array}{l}\text { Nizame et al. } 2016 \\
\text { [52] }\end{array}$ & Bangladesh & $\begin{array}{l}\text { Analysis of hygiene practices } \\
\text { during food preparation }\end{array}$ & $\begin{array}{c}12 \text { semi-structured } \\
\text { observations; } 12 \text { video } \\
\text { observations; } \\
12 \text { in-depth interviews; } \\
3 \text { focus group discussions }\end{array}$ & $\begin{array}{c}\text { Thematic coding informed by the } 15 \\
\text { factors of the } \\
\text { IBM-WASH model }\end{array}$ \\
\hline $\begin{array}{l}\text { Nizame et al. } 2019 \\
{[51]}\end{array}$ & Bangladesh & $\begin{array}{l}\text { Assessment of perceptions } \\
\text { regarding hand hygiene and } \\
\text { food handling in restaurants and } \\
\text { among food vendors }\end{array}$ & $\begin{array}{c}900 \text { structured } \\
\text { observations; } \\
64 \text { in-depth interviews }\end{array}$ & $\begin{array}{l}\text { Thematic coding; informed by three } \\
\text { dimensions and } \\
\text { four levels of the IBM-WASH model, } \\
\text { not considering the } \\
\text { structural/societal level }\end{array}$ \\
\hline $\begin{array}{l}\text { Yeasmin et al. } 2017 \\
\text { [49] }\end{array}$ & Bangladesh & $\begin{array}{l}\text { Identification of relevant factors } \\
\text { for improper disposal of trash } \\
\text { into communal toilets }\end{array}$ & $\begin{array}{c}\text { Phase I: } 10 \text { in-depth } \\
\text { interviews; } \\
\text { Phase II: } 6 \text { focus group } \\
\text { discussions ( } n=39) ; \\
\text { Phase III: } 24 \text { in-depth } \\
\text { interviews; } 2 \text { focus group } \\
\text { discussions }(n=18)\end{array}$ & $\begin{array}{l}\text { Thematic coding; informed by the } 15 \\
\text { factors of the IBM-WASH model }\end{array}$ \\
\hline $\begin{array}{l}\text { Hussain et al. } 2017 \\
\text { [46] }\end{array}$ & Bangladesh & $\begin{array}{l}\text { Analysis of advantages and } \\
\text { limitations of using double pit } \\
\text { latrines compared } \\
\text { to single pit latrines }\end{array}$ & $\begin{array}{l}18 \text { in-depth interviews; } \\
5 \text { focus group discussions } \\
\text { (8-9 members each) }\end{array}$ & $\begin{array}{c}\text { Thematic coding and categorizing } \\
\text { based on the three dimensions of the } \\
\text { IBM-WASH model (not } \\
\text { differentiating between levels) }\end{array}$ \\
\hline $\begin{array}{l}\text { George et al. } 2019 \\
{[48]}\end{array}$ & Bangladesh & $\begin{array}{l}\text { Evaluation of the feasibility and } \\
\text { acceptability of a mobile } \\
\text { health program for } \\
\text { diarrhea patients }\end{array}$ & $\begin{array}{l}40 \text { semi-structured } \\
\text { interviews; } 2 \text { group } \\
\text { discussions }(n=19)\end{array}$ & $\begin{array}{c}\text { Thematic coding; informed by the } 15 \\
\text { factors of the } \\
\text { IBM-WASH model }\end{array}$ \\
\hline \multicolumn{5}{|c|}{ Studies conducted in South America } \\
\hline $\begin{array}{l}\text { Rothstein et al. } \\
\quad 2015 \text { [53] }\end{array}$ & Peru & $\begin{array}{l}\text { Exploration of barriers to } \\
\text { drinking water chlorination }\end{array}$ & $\begin{array}{l}18 \text { in-depth interviews; } \\
18 \text { indirect observations; } \\
1 \text { focus group discussion } \\
\quad(n=5) ; 4 \text { interviews }\end{array}$ & $\begin{array}{l}\text { Qualitative coding; deductive codes } \\
\text { and inductive codes based on the } 15 \\
\text { factors of the IBM-WASH model }\end{array}$ \\
\hline $\begin{array}{l}\text { Rothstein et al. } \\
\quad 2019 \text { [54] }\end{array}$ & Peru & $\begin{array}{l}\text { Evaluation of baby bottle } \\
\text { contamination and analysis } \\
\text { of options to improve } \\
\text { bottle hygiene }\end{array}$ & $\begin{array}{l}48 \text { semi-structured } \\
\text { interviews }\end{array}$ & $\begin{array}{l}\text { Directed content analysis with focus } \\
\text { on the three dimensions of the } \\
\text { IBM-WASH model (not } \\
\text { differentiating between levels) }\end{array}$ \\
\hline $\begin{array}{l}\text { Lopez et al. } 2019 \\
\qquad[55]\end{array}$ & Ecuador & $\begin{array}{l}\text { Characterization of determinants } \\
\text { of latrine use }\end{array}$ & $\begin{array}{l}\text { Quantitative questionnaire } \\
\text { survey }(n=197)\end{array}$ & $\begin{array}{l}\text { Logistic regression modeling; } \\
\text { considering the psychosocial and } \\
\text { technological dimensions and } \\
\text { interpersonal, individual and } \\
\text { habitual levels of the } \\
\text { IBM-WASH model }\end{array}$ \\
\hline
\end{tabular}

\section{Appendix B}

Examples of our data that are presented as anchors were chosen using the following criteria: Each aspect of a factor that appeared in our data is illustrated by one example, from either the health $(\mathrm{H})$ or the land-use $(\mathrm{L})$ context. The index number indicates the course of action the study participant is referring to Niens et al. [10]. Where applicable, we chose examples that are comprehensible without knowing the questionnaire and where the categorization was clear for both coders. Each citation is followed by the individual pseudonym of the participant, the line number of the corresponding transcribed thinkaloud protocol, and the aspect of the factor it refers to. 
Table A2. Coding system for the qualitative analysis of the think-aloud protocols based on the IBM-WASH model by Dreibelbis et al. [14] with 3 dimensions and 5 levels. The 15 resulting factors are presented by level. Each factor is described by a coding guideline, with key points describing different aspects of the factor. Inductive adaptations of the IBM-WASH model as well as teacher quotes are in italics. Characteristics of a factor that were taken over from the original IBM-WASH model but not applicable to our data are grey. The table includes substantial contributions by Schneider [66].

\begin{tabular}{|c|c|c|c|}
\hline Level & Factor & Coding Guideline & Example (Anchor) \\
\hline \multirow{3}{*}{ 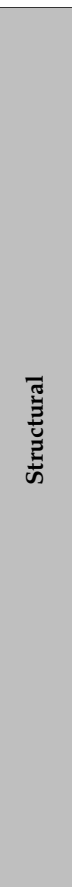 } & Structural-Contextual & $\begin{array}{l}\text { Statements regarding contextual conditions and a } \\
\text { factor on structural level that is predominantly } \\
\text { constant and unchangeable in the form of: } \\
\text { - } \quad \text { policy and regulations (as well as their } \\
\text { implementation); } \\
\text { - climate, geography, ecology. }\end{array}$ & $\begin{array}{l}\text { H.23c: "Implementation in urban life, this is easy to implement } \\
\text { because it is there where one can see more security forces, thus, it } \\
\text { is easy to implement." } \\
\text { [AF-11, 194-196] } \\
\text { (Policy and regulations as well as their implementation) } \\
\text { L.10c: "Implementation in rural life, this is possible to } \\
\text { implement. In the village, there [...] it is possible. For example, } \\
\text { it is possible to find rice seed of good quality but often there are } \\
\text { insects that eat the rice there and [ ... ] one does not find a lot the } \\
\text { good [seed] qualities, even if one takes his/her own seeds." } \\
\text { [Y-02, 417-420] } \\
\text { (Climate, geography, ecology) }\end{array}$ \\
\hline & Structural-Psychosocial & $\begin{array}{l}\text { Statements regarding a psychosocial factor on the } \\
\text { structural level } \\
\text { in the form of: } \\
\text { - leadership, advocacy; } \\
\text { - cultural identity, ethnic traditions, } \\
\quad \text { and taboos. }\end{array}$ & $\begin{array}{l}\text { L.20c: "There is also the alafady [forest that is taboo]. It is } \\
\text { difficult for the people to not enter the alafady and often the land } \\
\text { to cultivate is still this one. [ ... ] Sometimes, the people do not } \\
\text { have other land to cultivate, there is only this one. So, it is a bit } \\
\text { difficult to implement." } \\
\text { [M-05, 437-439] } \\
\text { (cultural identity, ethnic traditions, and taboos) }\end{array}$ \\
\hline & Structural-Technological & $\begin{array}{l}\text { Statements about a factor regarding the } \\
\text { application of a product or the technical feasibility } \\
\text { of a course of action on the structural level in the } \\
\text { form of: } \\
\text { - manufacturing and financing of a } \\
\text { - product; } \\
\text { distribution of a product (e.g., by the state } \\
\text { - cun organization); } \\
\text { - promotion of a course of action (e.g., by } \\
\text { the state or an organization }\end{array}$ & $\begin{array}{l}\text { L.5c: "In the rural life, this can be implemented because the } \\
\text { agricultural society gives different plants, particularly to those } \\
\text { who do the tree nurseries for diverse plant types." } \\
\text { [L-07, 367-368] } \\
\text { (distribution of a product, e.g., by the state or an } \\
\text { organization) } \\
\text { H.18b: "This can be implemented also in the village because the } \\
\text { course of action for the pupils in the school is already running, in } \\
\text { particular, the deworming coming from the health center." } \\
\text { [L-07, 228-230] } \\
\text { (promotion of a course of action (e.g., by the state or } \\
\text { an organization)) }\end{array}$ \\
\hline 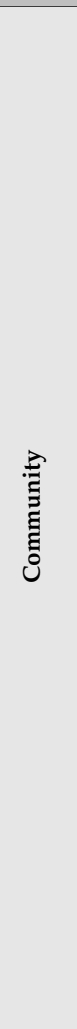 & Community-Contextual & $\begin{array}{l}\text { Statements regarding contextual conditions and a } \\
\text { factor on the community level in the form of: } \\
\text { - access to markets and/or the corresponding } \\
\text { product availability; } \\
\text { - access to resources; } \\
\text { - built/physical environment; } \\
\text { - access to products with supportive function } \\
\text { for the implementation of a course of action } \\
\text { - general available space/general available } \\
\text { arable land; } \\
\text { - general wealth; } \\
\text { - infrastructure. }\end{array}$ & 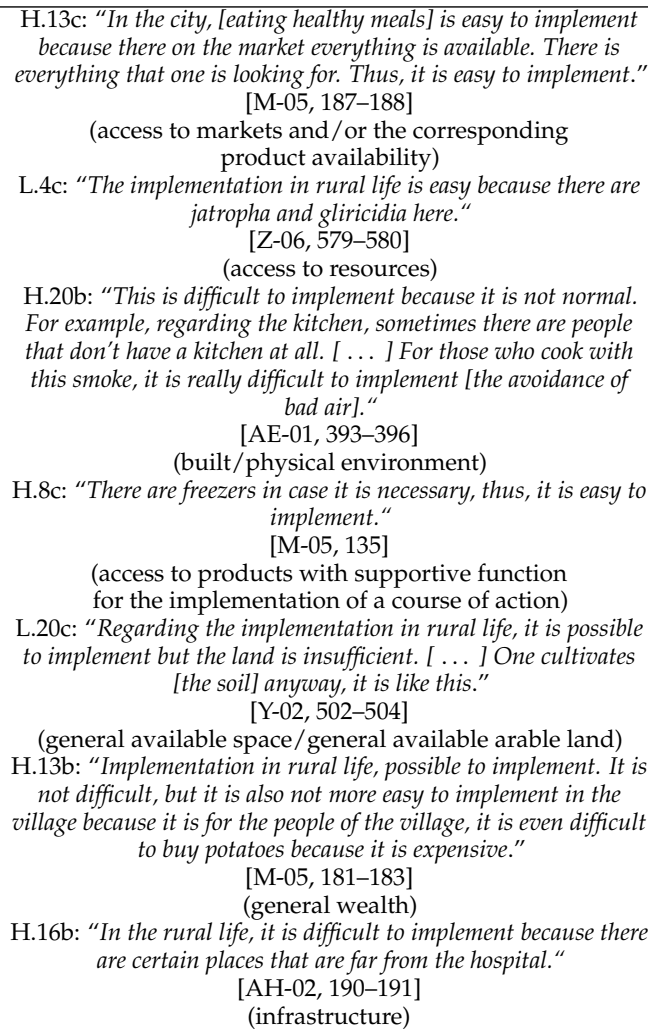 \\
\hline
\end{tabular}


Table A2. Cont.

\begin{tabular}{|c|c|c|c|}
\hline Level & Factor & Coding Guideline & Example (Anchor) \\
\hline \multirow[t]{2}{*}{ 茝 } & Community-Psychosocial & $\begin{array}{l}\text { Statements regarding a psychosocial factor on the } \\
\text { community level in the form of: } \\
\text { - shared values and/or attitudes; } \\
-\quad \text { collective efficacy; } \\
\text { - social integration; } \\
\text { - stigma; } \\
\text { - prevalent emotions; } \\
\text { - missing shared knowledge; } \\
\text { - missing shared awareness; } \\
\text { - shared awareness. }\end{array}$ & $\begin{array}{l}\text { H.16b: "In the bush, it is difficult to implement because until } \\
\text { now, there still exist people that are still not convinced to go to } \\
\text { the doctor. Thus, it is still a bit difficult [... ] generally to } \\
\text { implement these things." } \\
\text { [M-05, 214-216] } \\
\text { (shared values and/or attitudes) } \\
\text { H.22b: "The implementation in rural life, regarding the } \\
\text { pedestrians and the fast vehicles on the streets, it is easy to } \\
\text { implement. The people are scared of this." } \\
\text { [Z-06, 430-431] } \\
\text { (prevalent emotions) } \\
\text { L.8c "Sometimes, like us here in the village, we don't know how } \\
\text { to distinguish all this." } \\
\text { [AC-14, 666-667] } \\
\text { (missing shared knowledge) } \\
\text { H.8b: "Implementation in rural life, this is easy to implement } \\
\text { because [.. ] the people in the villages know how to make jam." } \\
\text { [AH-02, 117-118] } \\
\text { (shared knowledge) } \\
\text { H.12b: "Regarding the implementation in rural life, I would say } \\
\text { this is difficult to implement [handwashing with hends-free } \\
\text { constructions such as tippy-taps] because many people don't } \\
\text { think about constructing this thing." } \\
\text { [AC-07, 230-231] } \\
\text { (missing shared awareness) } \\
\text { L.22c: "Because [having plants with big roots at riversides], this } \\
\text { is easy to implement with simply the sensitization of the people. } \\
\text { Because this is a a advantage for everyone, thus it is good, the } \\
\text { sensitization to implement it in the village." } \\
\text { [AC-14, 890-892] } \\
\text { (shared awareness) }\end{array}$ \\
\hline & Community-Technological & $\begin{array}{l}\text { Statements about a factor regarding the } \\
\text { application of a product or the technical feasibility } \\
\text { of a course of action on the community level that } \\
\text { specifically refers to the product or the course of } \\
\text { action itself in the form of: } \\
\text { - location/access/availability of the } \\
\text { product that is indispensable for the } \\
\text { implementation of a course of action and } \\
\text { without the reason of the access/availability } \\
\text { being in the focus; } \\
\text { - individual vs. collective } \\
\text { ownership/access; } \\
\text { - maintenance of the product. }\end{array}$ & $\begin{array}{l}\text { L.11c: "This can be implemented also in the village because there } \\
\text { also exists rice seeds of good quality to sell or to distribute that } \\
\text { the state provides for the smallholders." } \\
\text { [L-07, } 439-440] \\
\text { (location/access/availability of the product that is } \\
\text { indispensable for the implementation of a course of action } \\
\text { and without the reason of the access/ availability being in } \\
\text { the focus) } \\
\text { H.11c: "This is easy to implement in the city. Everyone owns a } \\
\text { mosquito net." } \\
\text { [Z-06, 271-272] } \\
\text { (individual vs. collective ownership) }\end{array}$ \\
\hline \multirow{3}{*}{ 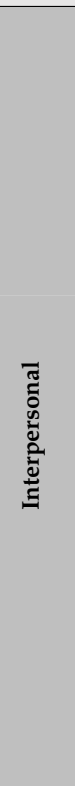 } & Interpersonal-Contextual & $\begin{array}{l}\text { Statements regarding contextual conditions that } \\
\text { result from interactions between (two or more) } \\
\text { individuals with a close, personal relationship in } \\
\text { the form of: } \\
\text { - roles and responsibilities; } \\
\text { - household structure; } \\
\text { - division of labor; } \\
\text { - available space/available arable land on } \\
\text { household level. }\end{array}$ & $\begin{array}{l}\text { L.13c: "And [the small house garden] is right next to the house } \\
\text { to not disturb the cultivators." } \\
\text { [L-07, } 459-460] \\
\text { (available space/available arable land on household level) }\end{array}$ \\
\hline & Interpersonal-Psychosocial & $\begin{array}{l}\text { Statements regarding a psychosocial factor that } \\
\text { results from interactions between (two or more) } \\
\text { individuals with a close, personal relationship in } \\
\text { the form of: } \\
\text { - injunctive or descriptive norms; } \\
\text { - aspirations; } \\
\text { - shame; } \\
\text { - nurture. }\end{array}$ & [no coding] \\
\hline & Interpersonal-Technological & $\begin{array}{l}\text { Statements about a factor regarding the } \\
\text { application of a product or the technical feasibility } \\
\text { of a course of action that results from interactions } \\
\text { between (two or more) individuals with a close, } \\
\text { personal relationship in the form of: } \\
\text { - sharing of access to product; } \\
\text { - modeling/demonstrating; use of } \\
\text { the product. }\end{array}$ & [no coding] \\
\hline
\end{tabular}


Table A2. Cont.

\begin{tabular}{|c|c|c|c|}
\hline Level & Factor & Coding Guideline & Example (Anchor) \\
\hline \multirow[b]{3}{*}{ 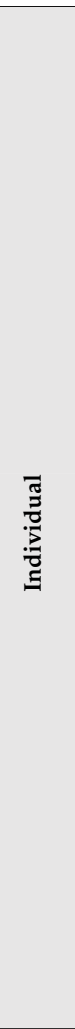 } & Individual-Contextual & $\begin{array}{l}\text { Statements regarding contextual conditions and a } \\
\text { factor that concerns the individual as well as its } \\
\text { sociodemographic data in the form of: } \\
\text { - individual wealth; } \\
\text { - age; } \\
\text { - education; } \\
\text { - gender; } \\
\text { - livelihoods/employment. }\end{array}$ & $\begin{array}{l}\text { H.13c: "In the urban life, [avoiding malnutrition] is difficult to } \\
\text { implement. Difficult to implement because all this is to buy. } \\
\text { If you don't have the money, you won't have it." } \\
\text { [AH-02,173-174] } \\
\text { (individual wealth) }\end{array}$ \\
\hline & Individual-Psychosocial & $\begin{array}{l}\text { Statements regarding a psychosocial factor of the } \\
\text { individual about themself or other single persons } \\
\text { in the form of: } \\
\text { - self-efficacy; } \\
\text { - disgust; } \\
\text { - perceived threat. }\end{array}$ & [no coding] \\
\hline & Individual-Technological & $\begin{array}{l}\text { Statements about a factor regarding the } \\
\text { application of a product or the technical feasibility } \\
\text { of a course of action in the form of individual } \\
\text { cognitive reflection on strengths and/or } \\
\text { weaknesses: } \\
\text { - perceived cost/value/cost-benefit relation; } \\
\text { - perceived convenience; } \\
\text { - ease of execution; } \\
\text { - difficulty of execution. }\end{array}$ & $\begin{array}{l}\text { L.9c: "In the rural life, this is also easy to implement [... ] to } \\
\text { have other plants to cultivate other than vanilla like coffee or } \\
\text { cacao because one can also have more products with the coffee and } \\
\text { the cacao." } \\
\text { [L-07, 407-409] } \\
\text { (perceived cost/value/cost-benefit relation) } \\
\text { H.2b: "Then, sometimes, it happens that, if it is Colgate or } \\
\text { toothpaste, they are not at all adapted to tooth care." } \\
\text { [M-05, 40-41] } \\
\text { (perceived convenience) } \\
\text { H.5b: "Implementation in the rural life, [respecting the hygiene } \\
\text { rules for water use] is possible to implement. It is possible to } \\
\text { implement because it is so easy to boil water." } \\
\text { [AH-02, 86-87] } \\
\text { (ease of execution) } \\
\text { L.2c: "It is a bit difficult to cut all these trees, like, for example, } \\
\text { the big bamboo, the water hyacinth, the lantana camara. It is } \\
\text { possible to implement." } \\
\text { [Y-02, 295-297] } \\
\text { (difficulty of execution) }\end{array}$ \\
\hline \multirow{3}{*}{ 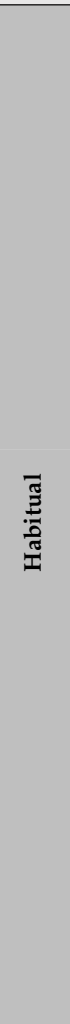 } & Habitual-Contextual & $\begin{array}{l}\text { Statements regarding contextual conditions and a } \\
\text { factor that explicitly relates to: } \\
\text { - favorable environment for habit } \\
\text { formation; } \\
\text { - opportunity for and barriers to repetition } \\
\text { of behavior. }\end{array}$ & $\begin{array}{l}\text { H.19c: "Implementation in the city. [Latrine use] is also easy to } \\
\text { implement because in the big city, the site is already narrow, thus } \\
\text { there is not space anymore to do the open cabin, therefore one } \\
\text { needs to do the normal cabin at a well-situated and safe place to } \\
\text { construct. And change the water if it stayed for a long time in the } \\
\text { cabin and use clean water if one uses the cabin." } \\
\text { [L-07, 240-244] } \\
\text { (favorable environment for habit formation) } \\
\text { L.1c: "The fact that [natural vegetation development on } \\
\text { non-cultivated plots] is not easy to implement is that the land is } \\
\text { already scarce so that the people cannot let the vegetation develop } \\
\text { to do the cultivation later. Yes, they cultivate this year and they } \\
\text { still cultivate next year, this is always like this but it is still } \\
\text { possible to implement." } \\
\text { [Y-02, 287-290] } \\
\text { (opportunity for and barriers to repetition of behavior) }\end{array}$ \\
\hline & Habitual-Psychosocial & $\begin{array}{l}\text { Statements regarding } \\
\text { a psychosocial factor } \\
\text { in the form of: } \\
\text { - existing habits; } \\
\text { - existing practices. }\end{array}$ & $\begin{array}{l}\text { H.21b: "Or use the gloves to work (text of the questionnaire) } \\
\text { [with pesticides] no, no, they just use their hands. Wear working } \\
\text { suits (text of the questionnaire), the people just wear these kind of } \\
\text { very old clothes that are almost unusable. They only wear bad } \\
\text { clothes, these are bad clothes that they wear to go working." } \\
\text { [AE-01, 414-417] } \\
\text { (existing habits) } \\
\text { L.21c: "Regarding the implementation [of adapting the } \\
\text { cultivation to the soil condition] in rural life, this is also easy to } \\
\text { implement this kind of plantation because there are already many } \\
\text { different plantations that the farmers manage in the village." } \\
\text { [L-07,537-539] } \\
\text { (existing practices) }\end{array}$ \\
\hline & Habitual-Technological & $\begin{array}{l}\text { Statements about a factor regarding the } \\
\text { application of a product or the technical feasibility } \\
\text { of a course of action regarding potential habits in } \\
\text { the form of: } \\
\text { - ease/effectiveness of routine use of } \\
\text { product/implementation of a course } \\
\text { of action. }\end{array}$ & $\begin{array}{c}\text { L.7c: "In the rural life, the uprooting of vanilla lianas is easy to } \\
\text { implement because many persons have had advantages for this } \\
\text { method of cultivating vanilla." } \\
\text { [L-07,388-390] } \\
\text { (ease/effectiveness of routine use of } \\
\text { product/implementation } \\
\text { of a course of action) }\end{array}$ \\
\hline
\end{tabular}

$(\mathrm{H}=$ health context; $\mathrm{L}=$ land-use context $)$. 


\section{References}

1. UNESCO. Education for Sustainable Development Goals: Learning Objectives, Paris, France. 2017. Available online: https: //www.unesco.de/sites/default/files/2018-08/unesco_education_for_sustainable_development_goals.pdf (accessed on 23 June 2021).

2. UN. Transforming Our World: The 2030 Agenda for Sustainable Development. Available online: https:/ / sustainabledevelopment. un.org/post2015/transformingourworld (accessed on 4 June 2021).

3. UNESCO. Global Education Monitoring Report 2020: Inclusion and Education: All Means All; Paris, France. 2020. Available online: https:/ / unesdoc.unesco.org/ark:/48223/pf0000373718 (accessed on 25 November 2021).

4. UNDP. Human Development Report 2019: Beyond Income, beyond Averages, beyond Today: Inequalities in Human Development in the 21st Century; New York, NY, USA. 2019. Available online: http://hdr.undp.org/sites/default/files/hdr2019.pdf (accessed on 25 November 2021).

5. Venart, L.C.; Reuter, K.E. Education in Madagascar: A Guide on the State of the Educational System, Needed Reforms and Strategies for Improvement. UOM Res. J. 2014, 20, 196-235.

6. UNESCO. SDG 4-Education 2030: Part II: Education for Sustainable Development Beyond 2019206 EX/6.II, Paris, France. 2019. Available online: https://www.bne-portal.de/sites/default/files/draft_framework_esd_annex_eng.pdf (accessed on 9 June 2020).

7. MSP. Plan de Développement du Secteur Santé 2015-2019, Antananarivo, Madagascar. 2015. Available online: https:/ / extranet. who.int/countryplanningcycles/sites/default/files/planning_cycle_repository/madagascar/pdss_2015.pdf (accessed on 11 August 2021).

8. Zaehringer, J.G.; Schwilch, G.; Andriamihaja, O.R.; Ramamonjisoa, B.; Messerli, P. Remote sensing combined with social-ecological data: The importance of diverse land uses for ecosystem service provision in north-eastern Madagascar. Ecosyst. Serv. 2017, 25, 140-152. [CrossRef]

9. Andriamihaja, O.R.; Metz, F.; Zaehringer, J.G.; Fischer, M.; Messerli, P. Land Competition under Telecoupling: Distant Actors' Environmental versus Economic Claims on Land in North-Eastern Madagascar. Sustainability 2019, 11, 851. [CrossRef]

10. Niens, J.; Richter-Beuschel, L.; Bögeholz, S. Land-Use and Health Issues in Malagasy Primary Education-A Delphi Study. Sustainability 2020, 12, 6212. [CrossRef]

11. Niens, J.; Richter-Beuschel, L.; Stubbe, T.C.; Bögeholz, S. Procedural Knowledge of Primary School Teachers in Madagascar for Teaching and Learning towards Land-Use- and Health-Related Sustainable Development Goals. Sustainability 2021, $13,9036$. [CrossRef]

12. Schüßler, D.; Richter, T.; Mantilla-Contreras, J. Educational Approaches to Encourage Pro-Environmental Behaviors in Madagascar. Sustainability 2019, 11, 3148. [CrossRef]

13. Vare, P.; Scott, W. Learning for a Change. J. Educ. Sustain. Dev. 2007, 1, 191-198. [CrossRef]

14. Dreibelbis, R.; Winch, P.J.; Leontsini, E.; Hulland, K.R.; Ram, P.K.; Unicomb, L.; Luby, S.P. The Integrated Behavioural Model for Water, Sanitation, and Hygiene: A systematic review of behavioural models and a framework for designing and evaluating behaviour change interventions in infrastructure-restricted settings. BMC Public Health 2013, 13, 1015. [CrossRef] [PubMed]

15. PASEC. PASEC 2019 Qualité des Systèmes Educatifs en Afrique Subsaharienne Francophone: Performances et Environnement de L'Enseignement-Apprentissage au Primare; Dakar, Senegal. 2020. Available online: https://www.confemen.org/wp-content/ uploads/2020/12/RapportPasec2019_Web.pdf (accessed on 25 November 2021).

16. MEN. Programmes Scolaires, Antananarivo, Madagascar. 2015. Available online: https://www.education.gov.mg/systemeeducatif/primaire/ (accessed on 9 June 2020).

17. Brias-Guinart, A.; Pyhälä, A.; Cabeza, M. Linking biodiversity conservation and education: Perspectives from education programmes in Madagascar. Madag. Conserv. Dev. 2020, 15, 35-39. [CrossRef]

18. MEN; MESUPRES; MEETFP. Plan Sectoriel de l'Éducation: (2018-2022), Madagascar. 2017. Available online: https://www. globalpartnership.org/sites/default/files/a2_-_mad_-_esp_fr.pdf (accessed on 9 June 2020).

19. Reibelt, L.M.; Richter, T.; Waeber, P.O.; Rakotoarimanana, S.; Mantilla-Contreras, J. Environmental education in its infancy at Lake Alaotra, Madagascar. Madag. Conserv. Dev. 2014, 9, 71-82. [CrossRef]

20. Niens, J.; Schwarzer, C.; Bögeholz, S. Rahmenbedingungen, Voraussetzungen und Potentiale für Bildung für Nachhaltige Entwicklung in Grundschulen im Nordosten Madagaskars. In Treffpunkt Biologische Vielfalt XVII, Proceedings of the Interdisziplinärer Forschungsaustausch im Rahmen des Übereinkommens über die Biologische Vielfalt, Vilm, Germany, 19-23 August 2018; Korn, H., Dünnfelder, H., Eds.; Bundesamt für Naturschutz: Bonn, Germany, 2019; pp. 9-15. ISBN 978-3-89624-264-8.

21. Symrise. Symrise, Unilever and GIZ Join Forces with Save the Children-To Support Vanilla Farming Communities in Madagascar. Available online: https://www.symrise.com/newsroom/article/symrise-unilever-and-giz-join-forces-with-save-the-children/ (accessed on 16 December 2020).

22. UNICEF Madagascar. Madagascar: Cyclone Enawo Update No 1. 2017. Available online: https://www.humanitarianresponse. info/sites/www.humanitarianresponse.info/files/documents/files/unicef_madagascar_cyclone_enawo_update1--17march2 017.pdf (accessed on 16 December 2020).

23. Hernandez, O. Assessment of Hygiene Promotion in Madagascar 2007-2008 Comparisons for Households, Schools, and Health Facilities; USAID Hygiene Improvement Project: Washington, DC, USA, 2009. 
24. Tearfund. Sanitation and Hygiene in Developing Countries: Identifying and Responding to Barriers: A Case Study from Madagascar. 2007. Available online: https://www.humanitarianlibrary.org/resource/sanitation-and-hygiene-developingCountries-Identifying-and-Responding-Barriers-Case-0 (accessed on 9 April 2021).

25. Dolins, F.L.; Jolly, A.; Rasamimanana, H.; Ratsimbazafy, J.; Feistner, A.T.C.; Ravoavy, F. Conservation education in Madagascar: Three case studies in the biologically diverse island-continent. Am. J. Primatol. 2010, 72, 391-406. [CrossRef]

26. Rakotomamonjy, S.N.; Jones, J.P.G.; Razafimanahaka, J.H.; Ramamonjisoa, B.; Williams, S.J. The effects of environmental education on children's and parents' knowledge and attitudes towards lemurs in rural Madagascar. Anim. Conserv. 2015, 18, 157-166. [CrossRef]

27. Simons, E.; Meyers, D.M. Folklore and beliefs about the aye aye (Daubentonia madagascariensis). Lemur News 2001, 6, 11-16.

28. INSTAT. Enquête Périodique auprès de Ménages: Rapport Principal, Antananarivo, Madagascar. 2011. Available online: https:/ / www.instat.mg/wp-content/uploads/2016/11/INSTAT_Epm2010-08-2011.pdf (accessed on 10 June 2020).

29. Curtis, V.A.; Danquah, L.O.; Aunger, R.V. Planned, motivated and habitual hygiene behaviour: An eleven country review. Health Educ. Res. 2009, 24, 655-673. [CrossRef] [PubMed]

30. Andrianarisoa, A.; Rakotoson, J.; Randretsa, M.; Rakotondravelo, S.; Rakotoarimanana, R.D.; Rakotomizao, J.; Aubry, P. Madagascar: La situation sanitaire dans la grande île au début du XXIe siècle. Med. Trop. 2007, 67, 19-29.

31. Meekers, D.; Yukich, J.O. The association between household bed net ownership and all-cause child mortality in Madagascar. Malar. J. 2016, 15, 475. [CrossRef]

32. Andriamparany, J.N.; Hänke, H.; Schlecht, E. Food security and food quality among vanilla farmers in Madagascar: The role of contract farming and livestock keeping. Food Sec. 2021. Available online: https://link.springer.com/article/10.1007/s12571-021 -01153-z (accessed on 25 November 2021). [CrossRef]

33. Hänke, H.; Barkmann, J.; Blum, L.; Franke, Y.; Martin, D.A.; Niens, J.; Osen, K.; Uruena, V.; Witherspoon, S.A.; Wurz, A. Socio-Economic, Land Use and Value Chain Perspectives on Vanilla Farming in the SAVA Region (North-Eastern Madagascar): The Diversity Turn Baseline Study (DTBS), July 2019 ed.; Discussion paper No. 1806; DARE: Goettingen, Germany, 2018.

34. Martin, D.A.; Wurz, A.; Osen, K.; Grass, I.; Hölscher, D.; Rabemanantsoa, T.; Tscharntke, T.; Kreft, H. Shade-Tree Rehabilitation in Vanilla Agroforests is Yield Neutral and May Translate into Landscape-Scale Canopy Cover Gains. Ecosystems 2020. Available online: https: / /link.springer.com/article/10.1007/s10021-020-00586-5 (accessed on 25 November 2021). [CrossRef]

35. Martin, D.A.; Andriafanomezantsoa, R.; Dröge, S.; Osen, K.; Rakotomalala, E.; Wurz, A.; Andrianarimisa, A.; Kreft, H. Bird diversity and endemism along a land-use gradient in Madagascar: The conservation value of vanilla agroforests. Biotropica 2021, 53, 179-190. [CrossRef]

36. Jones, J.P.G.; Ratsimbazafy, J.; Ratsifandrihamanana, A.N.; Watson, J.E.M.; Andrianandrasana, H.T.; Cabeza, M.; Cinner, J.E.; Goodman, S.M.; Hawkins, F.; Mittermeier, R.A.; et al. Last chance for Madagascar's biodiversity. Nat. Sustain. 2019, 2, 350-352. [CrossRef]

37. Vieilledent, G.; Grinand, C.; Rakotomalala, F.A.; Ranaivosoa, R.; Rakotoarijaona, J.-R.; Allnutt, T.F.; Achard, F. Combining global tree cover loss data with historical national forest cover maps to look at six decades of deforestation and forest fragmentation in Madagascar. Biol. Conserv. 2018, 222, 189-197. [CrossRef]

38. Ganzhorn, J.U.; Lowry, P.P.; Schatz, G.E.; Sommer, S. The biodiversity of Madagascar: One of the world's hottest hotspots on its way out. Oryx 2001, 35, 346-348. [CrossRef]

39. Laney, R.; Turner, B.L. The Persistence of Self-Provisioning Among Smallholder Farmers in Northeast Madagascar. Hum. Ecol. Interdiscip. J. 2015, 43, 811-826. [CrossRef] [PubMed]

40. Brand, J.; Pfund, J. Site- and watershed-level assessment of nutrient dynamics under shifting cultivation in eastern Madagascar. Agric. Ecosyst. Environ. 1998, 71, 169-183. [CrossRef]

41. Urech, Z.L.; Zaehringer, J.G.; Rickenbach, O.; Sorg, J.-P.; Felber, H.R. Understanding deforestation and forest fragmentation from a livelihood perspective. Madag. Conserv. Dev. 2015, 10, 67-76. [CrossRef]

42. Mosler, H.-J. A systematic approach to behavior change interventions for the water and sanitation sector in developing countries: A conceptual model, a review, and a guideline. Int. J. Environ. Health Res. 2012, 22, 431-449. [CrossRef]

43. Figueroa, M.E.; Kincaid, D.L. Social, Cultural and Behavioral Correlates of Household Water Treatment and Storage; Center Publication HCI 2010-1: Health Communication Insights; Johns Hopkins Bloomberg School of Public Health, Center for Communication Programs: Baltimore, MD, USA, 2010; Available online: https:/ /ccp.jhu.edu/wp-content/uploads/2014/11/Household-WaterTreatment-and-Storage-2010.pdf (accessed on 18 June 2021).

44. Hulland, K.R.S.; Leontsini, E.; Dreibelbis, R.; Unicomb, L.; Afroz, A.; Dutta, N.C.; Nizame, F.A.; Luby, S.P.; Ram, P.K.; Winch, P.J. Designing a handwashing station for infrastructure-restricted communities in Bangladesh using the integrated behavioural model for water, sanitation and hygiene interventions (IBM-WASH). BMC Public Health 2013, 13, 877. [CrossRef] [PubMed]

45. Sultana, F.; Unicomb, L.E.; Nizame, F.A.; Dutta, N.C.; Ram, P.K.; Luby, S.P.; Winch, P.J. Acceptability and Feasibility of Sharing a Soapy Water System for Handwashing in a Low-Income Urban Community in Dhaka, Bangladesh: A Qualitative Study. Am. J. Trop. Med. Hyg. 2018, 99, 502-512. [CrossRef] [PubMed]

46. Hussain, F.; Clasen, T.; Akter, S.; Bawel, V.; Luby, S.P.; Leontsini, E.; Unicomb, L.; Barua, M.K.; Thomas, B.; Winch, P.J. Advantages and limitations for users of double pit pour-flush latrines: A qualitative study in rural Bangladesh. BMC Public Health 2017, 17, 515. [CrossRef] 
47. Najnin, N.; Arman, S.; Abedin, J.; Unicomb, L.; Levine, D.I.; Mahmud, M.; Leder, K.; Yeasmin, F.; Luoto, J.E.; Albert, J.; et al. Explaining low rates of sustained use of siphon water filter: Evidence from follow-up of a randomised controlled trial in Bangladesh. Trop. Med. Int. Health 2015, 20, 471-483. [CrossRef]

48. George, C.M.; Zohura, F.; Teman, A.; Thomas, E.; Hasan, T.; Rana, S.; Parvin, T.; Sack, D.A.; Bhuyian, S.I.; Labrique, A.; et al. Formative research for the design of a scalable water, sanitation, and hygiene mobile health program: CHoBI7 mobile health program. BMC Public Health 2019, 19, 1028. [CrossRef]

49. Yeasmin, F.; Luby, S.P.; Saxton, R.E.; Nizame, F.A.; Alam, M.-U.; Dutta, N.C.; Masud, A.-A.; Yeasmin, D.; Layden, A.; Rahman, H.; et al. Piloting a low-cost hardware intervention to reduce improper disposal of solid waste in communal toilets in low-income settlements in Dhaka, Bangladesh. BMC Public Health 2017, 17, 682. [CrossRef] [PubMed]

50. McMichael, C.; Robinson, P. Drivers of sustained hygiene behaviour change: A case study from mid-western Nepal. Soc. Sci. Med. 2016, 163, 28-36. [CrossRef]

51. Nizame, F.A.; Alam, M.U.; Masud, A.A.; Shoab, A.K.; Opel, A.; Islam, M.K.; Luby, S.P.; Unicomb, L. Hygiene in Restaurants and among Street Food Vendors in Bangladesh. Am. J. Trop. Med. Hyg. 2019, 101, 566-575. [CrossRef] [PubMed]

52. Nizame, F.A.; Leontsini, E.; Luby, S.P.; Nuruzzaman, M.; Parveen, S.; Winch, P.J.; Ram, P.K.; Unicomb, L. Hygiene Practices During Food Preparation in Rural Bangladesh: Opportunities to Improve the Impact of Handwashing Interventions. Am. J. Trop. Med. Hyg. 2016, 95, 288-297. [CrossRef] [PubMed]

53. Rothstein, J.D.; Leontsini, E.; Olortegui, M.P.; Yori, P.P.; Surkan, P.J.; Kosek, M. Determinants of Caregivers' Use and Adoption of Household Water Chlorination: A Qualitative Study with Peri-Urban Communities in the Peruvian Amazon. Am. J. Trop. Med. Hyg. 2015, 93, 626-635. [CrossRef] [PubMed]

54. Rothstein, J.D.; Mendoza, A.L.; Cabrera, L.Z.; Pachas, J.; Calderón, M.; Pajuelo, M.J.; Caulfield, L.E.; Winch, P.J.; Gilman, R.H. Household Contamination of Baby Bottles and Opportunities to Improve Bottle Hygiene in Peri-Urban Lima, Peru. Am. J. Trop. Med. Hyg. 2019, 100, 988-997. [CrossRef]

55. Lopez, V.K.; Berrocal, V.J.; Corozo Angulo, B.; Ram, P.K.; Trostle, J.; Eisenberg, J.N.S. Determinants of Latrine Use Behavior: The Psychosocial Proxies of Individual-Level Defecation Practices in Rural Coastal Ecuador. Am. J. Trop. Med. Hyg. 2019, 100, 733-741. [CrossRef]

56. Seimetz, E.; Boyayo, A.-M.; Mosler, H.-J. The Influence of Contextual and Psychosocial Factors on Handwashing. Am. J. Trop. Med. Hyg. 2016, 94, 1407-1417. [CrossRef]

57. Tamene, A.; Afework, A. Exploring barriers to the adoption and utilization of improved latrine facilities in rural Ethiopia: An Integrated Behavioral Model for Water, Sanitation and Hygiene (IBM-WASH) approach. PLoS ONE 2021, 16, e0245289. [CrossRef]

58. Alemu, F.; Kumie, A.; Medhin, G.; Gebre, T.; Godfrey, P. A socio-ecological analysis of barriers to the adoption, sustainablity and consistent use of sanitation facilities in rural Ethiopia. BMC Public Health 2017, 17, 706. [CrossRef] [PubMed]

59. Ericsson, K.A.; Simon, H.A. Protocol Analysis: Verbal Reports as Data, Revised edition; MIT Press: Cambridge, MA, USA, 1993; ISBN 0-262-05047-1.

60. Mambrey, S.; Schreiber, N.; Schmiemann, P. Young Students' Reasoning About Ecosystems: The Role of Systems Thinking, Knowledge, Conceptions, and Representation. Res. Sci. Educ. 2020. Available online: https://link.springer.com/article/10.1007/ s11165-020-09917-x (accessed on 25 November 2021). [CrossRef]

61. Rosenzweig, C.; Krawec, J.; Montague, M. Metacognitive strategy use of eighth-grade students with and without learning disabilities during mathematical problem solving: A think-aloud analysis. J. Learn. Disabil. 2011, 44, 508-520. [CrossRef] [PubMed]

62. Cowan, J. The potential of cognitive think-aloud protocols for educational action-research. Act. Learn. High. Educ. 2019, 20, 219-232. [CrossRef]

63. Jun Zhang, L.; Zhang, D. Think-Aloud protocols. In The Routledge Handbook of Research Methods in Applied Linguistics; McKinley, J., Rose, H., Eds.; Routledge: London, UK, 2020; pp. 302-312. ISBN 9781138501140.

64. Funke, J.; Spering, M. Methoden der Denk-und Problemlöseforschung. In Denken und Problemlösen; Funke, J., Ed.; Hogrefe: Göttingen, Germany, 2006; pp. 647-744. ISBN 9783801705275.

65. Mayring, P. Qualitative Inhaltsanalyse: Grundlagen und Techniken, 12th ed.; Beltz Verlag: Weinheim, Germany; Basel, Switzerland, 2015; ISBN 978-3-407-29393-0.

66. Schneider, R. Welche Faktoren determinieren Einschätzungen zur Umsetzbarkeit von Maßnahmen für die Gestaltung Nachhaltiger Entwicklung: Eine Studie Lauten Denkens zur Analyse von Wissen madagassischer Grundschullehrkräfte. Master's Thesis, Biology Education, Georg-August-Universität Göttingen, Göttingen, Germany, 2020.

67. Biswas, D.; Nizame, F.A.; Sanghvi, T.; Roy, S.; Luby, S.P.; Unicomb, L.E. Provision versus promotion to develop a handwashing station: The effect on desired handwashing behavior. BMC Public Health 2017, 17, 390. [CrossRef] [PubMed]

68. Döring, N.; Bortz, J. Forschungsmethoden und Evaluation in den Sozial-und Humanwissenschaften; Springer: Berlin/Heidelberg, Germany, 2016; ISBN 978-3-642-41088-8.

69. Sweat, M.; Kerrigan, D.; Moreno, L.; Rosario, S.; Gomez, B.; Jerez, H.; Weiss, E.; Barrington, C. Cost-effectiveness of environmentalstructural communication interventions for HIV prevention in the female sex industry in the Dominican Republic. J. Health Commun. 2006, 11 (Suppl. 2), 123-142. [CrossRef]

70. Lambin, E.F.; Meyfroidt, P. Global land use change, economic globalization, and the looming land scarcity. Proc. Natl. Acad. Sci. USA 2011, 108, 3465-3472. [CrossRef] [PubMed] 
71. Waeber, P.O.; Reibelt, L.M.; Randriamalala, I.H.; Moser, G.; Raveloarimalala, L.M.; Ralainasolo, F.B.; Ratsimbazafy, J.; Woolaver, L. Local awareness and perceptions: Consequences for conservation of marsh habitat at Lake Alaotra for one of the world's rarest lemurs. Oryx 2018, 52, 677-686. [CrossRef]

72. Bouriquet, G. Le Vanillier et la Vanille à Madagascar. Rev. Int. Bot. Appl. D'agric. Trop. 1946, 26, 298-404. [CrossRef]

73. Bustamante, N.D.; Golden, C.D.; Randrianasolo, J.F.; Parmar, P. A qualitative evaluation of health care in the Maroantsetra region of Madagascar. Int. Health 2019, 11, 185-192. [CrossRef]

74. Blanco, M.B.; Rudman, A.N.; Greene, L.K.; Razafindrainibe, F.; Andrianandrasana, L.; Welch, C. Back to basics: Gaps in baseline data call for revisiting an environmental education program in the SAVA region, Madagascar. PLoS ONE 2020, 15, e0231822. [CrossRef] [PubMed]

75. Korhonen, K.; Lappalainen, A. Examining the environmental awareness of children and adolescents in the Ranomafana region, Madagascar. Environ. Educ. Res. 2004, 10, 195-216. [CrossRef]

76. Niens, J. Bewertungen von (nachhaltigen) Betriebsstrategien im Vanilleanbau durch Grundschullehrkräfte der SAVARegion/Madagaskar. Master's Thesis, Biology Education, Georg-August-Universität Göttingen, Göttingen, Germany, 2017.

77. Ratompomalala, H.; Rajhonson, L.; Razafimbelo, J.; Rakotonanahary, M.L.; Razafimbelo, C. The Self-Representation of Primary School Teachers' Professional Identity in Madagascar. CICE Ser. 2019, 6, 161-173.

78. O'Connor, C.; Joffe, H. Intercoder Reliability in Qualitative Research: Debates and Practical Guidelines. Int. J. Qual. Methods 2020, 19. [CrossRef]

79. Neudert, R.; Ganzhorn, J.U.; Wätzold, F. Global benefits and local costs-The dilemma of tropical forest conservation: A review of the situation in Madagascar. Envir. Conserv. 2017, 44, 82-96. [CrossRef]

80. Green, L.W.; Richard, L.; Potvin, L. Ecological foundations of health promotion. Am. J. Health Promot. 1996, 10, 270-281. [CrossRef] 